Encontro Nacional de

Economia Industrial e Inovação
Indústria e Desenvolvimento Econômico:

desafios e perspectivas

18 a 20 de setembro de 2018

Uberlândia - Minas Gerais

\title{
TRANSTORNO DISSOCIATIVO DE IDENTIDADE: EXERCÍCIOS CONTRAFACTUAIS DE PRODUTIVIDADE MULTISSETORIAL DA ECONOMIA BRASILEIRA NO PERÍODO 2000-2014
}

\section{Tomás Amaral Torezani ${ }^{\star}$}

\begin{abstract}
Resumo: O presente trabalho tem como objetivo principal investigar alguns motivos estruturais que podem auxiliar na explicação do baixo nível de produtividade do Brasil no período 2000-2014 tanto em termos agregados quanto em uma perspectiva multissetorial. A partir da World Input-Output Database 2016 realizam-se algumas estimações contrafactuais da produtividade que permitem identificar se a produtividade brasileira seria maior caso apresentasse uma distribuição da estrutura de empregos semelhante à de outras economias, bem como se apresentasse níveis de produtividades semelhantes aos dessas economias. Os resultados obtidos sugerem que a alteração em qualquer dos dois casos traria ganhos potenciais para o Brasil em praticamente todos os setores e com praticamente todos os países tomados como referência. Entretanto, o Brasil seria ainda mais produtivo se as suas atividades econômicas tivessem o nível de produtividade setorial dos países de referência. Nesses termos, apreendese que o problema da baixa produtividade da economia brasileira das últimas décadas decorre fundamentalmente de fatores estruturais e sistêmicos, e não algo associado a setores específicos.
\end{abstract}

Palavras-chave: Produtividade do trabalho, exercícios contrafactuais, abordagem multissetorial, World Input-Output 2016, economia brasileira

\begin{abstract}
This article investigates some structural reasons that may help explain the low level of Brazilian productivity in 2000-2014 both in aggregate terms and multisectoral perspective. From the World Input-Output Database 2016, counterfactual productivities are estimated that allow us to identify whether Brazilian productivity would be higher if it had a similar distribution of the structure of jobs as in other economies or if it presented levels of productivity similar to those of these economies. The results suggest that the change in any of the two cases would bring potential gains for Brazil in practically all sectors and with practically all economies taken as reference. However, the gains would be much greater in the second case. Therefore, the problem of low productivity of the Brazilian economy in the last decades stems fundamentally from structural and systemic factors, rather than from specific sectors.
\end{abstract}

Keywords: Labour productivity, counterfactual exercises, multisectoral approach, World Input-Output 2016, Brazilian economy

Classificação JEL: O47, L16, O57

Área Temática 1: Indústria e competitividade

1.3 Crescimento, produtividade e competitividade

- Analista Pesquisador em Economia da Fundação de Economia e Estatística (FEE) e doutorando em Economia do PPGE/UFRGS. E-mail: tomas_torezani@hotmail.com 


\section{INTRODUÇÃO}

Uma regularidade empírica encontrada e bastante difundida na literatura de desenvolvimento econômico é a de que o desempenho de longo prazo de uma economia depende da sua capacidade em promover a mudança estrutural a partir das tendências da realocação de insumos e produtos de setores menos produtivos para aqueles com maiores dinamismos tecnológico (capacidade de absorver, criar e difundir a mudança tecnológica) e da demanda (FISHER, 1939; CLARK, 1940; KUZNETS, 1966; BAUMOL, 1967; CHENERY e SYRQUIN, 1975; CHENERY, ROBINSON e SYRQUIN, 1986; DUARTE e RESTUCCIA, 2010; HERRENDORF, ROGERSON e VALENTINYI, 2014).

Nesse contexto, uma série de trabalhos se voltou à análise do crescimento da produtividade agregada das economias a partir de técnicas de growth accounting, mais especificamente utilizando o método shift-share, tanto investigações para um conjunto de países (FAGERBERG, 2000; PIEPER, 2000; PENEDER, 2003; TIMMER e DE VRIES, 2009; OCAMPO, RADA e TAYLOR, 2009; McMILLAN e RODRIK, 2011; DE VRIES, TIMMER E DE VRIES, 2015) quanto para países específicos como o Brasil (BONELLI, 2002, 2014; CARVALHEIRO, 2003; ROCHA, 2007; SQUEFFE e DE NEGRI, 2013; JACINTO e RIBEIRO, 2015). Todos esses trabalhos estimam os determinantes do crescimento da produtividade agregada a partir de alguns componentes, geralmente um do tipo within (crescimento da produtividade agregada a partir do crescimento das produtividades setoriais) e outro do tipo between (crescimento da produtividade agregada a partir da realocação do emprego de atividades menos produtivos para aquelas mais produtivas).

O presente trabalho, por seu turno, investiga o nível e a evolução das produtividades agregada e setorial dentro de uma economia específica (no caso, o Brasil), mas, diferentemente dos estudos mencionados, a partir do cruzamento entre a estrutura do emprego e o nível da produtividade setorial entre diferentes países. Em outras palavras, pretende-se realizar algumas estimações contrafactuais da produtividade da economia brasileira supondo a produtividade setorial ou a estrutura da alocação do emprego de outras economias. Ressalta-se que essas estimações são feitas dentro de um mesmo período (ano), e não entre dois momentos distintos do tempo conforme realizado nas estimações dos crescimentos da produtividade agregada dos trabalhos mencionados anteriormente. Com isso, espera-se avaliar os ganhos ou perdas de produtividade caso a economia brasileira apresentasse uma estrutura de produção diferente da efetivamente alcançada, isto é, similar à de outras economias. Poucos foram os trabalhos que se debruçaram nessa questão, em especial, na análise do caso do Brasil.

Miguez e Moraes (2014), utilizando dados da Socio Economic Accounts da World Input-Output 2014 (SEA/WIOD 2014), investigam os níveis e a evolução da produtividade do trabalho de diversas atividades econômicas do Brasil e os comparam com o desempenho de quatro economias selecionadas, a saber, Estados Unidos, China, Alemanha e México ${ }^{1}$. Ademais, o estudo realiza uma decomposição do diferencial de produtividade para averiguar quais atividades contribuíram mais para a distância relativa em relação às quatro economias selecionadas, bem como um exercício contrafactual de "produtividade cruzada" com o intuito de medir qual seria o impacto em termos de produtividade agregada caso o Brasil passasse a possuir a estrutura de ocupações, ou a produtividade setorial, dos países utilizados como base de comparação ${ }^{2}$. A análise evidenciou que a posição do Brasil em termos de produtividade é bastante frágil e pode afetar seriamente sua capacidade de competição nos mercados internacionais. Adicionalmente, os autores encontram que a defasagem de produtividade da economia brasileira em relação aos países comparados é mais fortemente afetada pelos diferenciais de produtividade intrassetoriais, apesar de guardar uma considerável relação com a estrutura de empregos.

Uma ressalva importante é que o trabalho não corrige os valores monetários utilizados nos cálculos das produtividades por nenhum índice de paridade do poder de compra (PPP), o que propiciaria realizar uma análise mais criteriosa acerca dos diferenciais de produtividade e seus reflexos sobre a competividade dos países. Dessa forma, como os próprios autores indicam, níveis e variações distintos nos preços internos (de cada economia e de cada setor) podem provocar impactos significativos nas

\footnotetext{
${ }^{1}$ Segundo os autores, os três primeiros países identificados foram selecionados por corresponder aos principais parceiros comerciais do ponto de vista da origem das importações brasileiras, enquanto o México foi escolhido por se tratar tanto de um país latino-americano quanto por ter uma estrutura e desafios similares aos enfrentados pelo Brasil.

${ }^{2}$ A produtividade do trabalho é calculada a preços constantes (US\$) de 1995.
} 
análises comparativas de competitividade. Além do mais, o trabalho volta-se a comparar as atividades econômicas do Brasil com quatro países selecionados. Contudo, apesar de três das quatro economias selecionadas serem as maiores economias mundiais, a fronteira de produtividade de atividades econômicas específicas pode não ser definida por esses países, isto é, outras economias podem apresentar níveis mais elevados de produtividade em uma atividade particular.

Outro trabalho que também investiga a evolução da produtividade setorial brasileira e a comparada internacionalmente é o de Veloso et al. (2017). Utilizando a mesma base de dados e o mesmo exercício contrafactual de "produtividade cruzada" de Miguez e Moraes (2014), os autores avaliam a importância relativa da alocação do emprego e do nível da produtividade setorial para o comportamento da produtividade agregada e para a produtividade dos três macrossetores da economia (agropecuária, indústria e serviços). Diferentemente de Miguez e Moraes (2014), todavia, Veloso et al. (2017) trabalham, em um primeiro momento, com um índice de PPP agregado e, posteriormente, ao analisarem o setor de serviços, com PPPs setoriais ${ }^{3}$. Outra diferença é que os autores realizam os exercícios contrafactuais para todos os 40 países da base de dados. Os resultados dos autores indicam que, embora a produtividade da economia brasileira possa aumentar se a sua alocação setorial de trabalho se aproximar da observada nos países desenvolvidos, os ganhos potenciais são muito maiores caso a produtividade setorial brasileira convergisse para o nível observado nessas economias. Na investigação mais detalhada sobre o setor de serviços, os autores chegam às mesmas conclusões feitas anteriormente tanto em termos agregados quanto nos seus componentes de serviços tradicionais e modernos. Logo, os autores concluem que a baixa produtividade brasileira trata-se de um problema sistêmico e não algo associado a setores específicos.

O presente estudo pretende avançar em algumas áreas em relação a esses dois trabalhos. A principal delas consiste na atualização da base de dados utilizada, a SEA/WIOD 2016. As principais novidades em relação à base anterior consistem na maior desagregação das atividades econômicas (de 35 para 56 atividades) e na disponibilidade de dados mais recentes (enquanto a SEA/WIOD 2014 cobria o período 1995-2009, a SEA/WIOD 2016 abrange o período 2000-2014), permitindo captar ainda mais as heterogeneidade dentro e entre as atividades. Ademais, este trabalho utiliza conversores setoriais específicos para todas as atividades econômicas, permitindo realizar comparações internacionais entre diferentes setores da economia de forma mais criteriosa. Adicionalmente, trabalha-se com diferentes agregações setoriais para melhor identificar os padrões de comportamento da produtividade brasileira.

Em assim sendo, o objetivo do presente trabalho consiste em mensurar o diferencial de produtividade do Brasil quando comparado com diversas outras economias, com o intuito de identificar em que medida a baixa produtividade agregada do país está associada a diferenças no nível de produtividade individual das atividades ou na estrutura de ocupações de cada uma dessas atividades. Dessa forma, os exercícios contrafactuais realizados permitem avaliar a importância relativa da alocação do emprego e do nível da produtividade setorial para o comportamento da produtividade agregada em todos os anos disponíveis na base de dados. As estimativas são calculadas tanto para as 56 atividades quanto por diferentes agregações, tais como os três grandes macrossetores (agropecuária, indústria e serviços), desagregando-se a indústria em dois segmentos (indústria de transformação e outras indústrias), bem como os serviços (serviços tradicionais e serviços modernos ${ }^{4}$ ), dada a heterogeneidade interna desses setores. Além do mais, também se desagrega a economia em dois grandes setores (economia dual) de acordo com o potencial de contribuição de cada uma das 56 atividades econômicas para a dinâmica da produtividade agregada.

Para tanto, o restante do trabalho está estruturado da seguinte forma, além desta introdução: a seção 2 consiste em uma breve seção acerca da metodologia e da base de dados utilizada para os cálculos das produtividades cruzadas; a seção 3 expõe um panorama geral dos dados e os resultados obtidos; por fim, a última seção remete-se às considerações finais do trabalho.

\footnotetext{
${ }^{3}$ A produtividade do trabalho é calculada a preços constantes internacionais (US\$ PPP) de 2005.

${ }^{4} \mathrm{O}$ setor moderno da economia consiste nas atividades pertencentes à indústria e aos serviços tradables.
} 


\section{CONSIDERAÇÕES METODOLÓGICAS E BASE DE DADOS}

Os dados utilizados nesse trabalho são provenientes do projeto World Input-Output Database (WIOD). O cerne da WIOD consiste na elaboração de uma Matriz de Insumo-Produto (MIP) mundial com base em séries temporais de Tabelas de Recursos e Usos (TRUs) nacionais e internacionais e de contas satélites mundiais como as Contas Socioeconômicas (Socio Economic Accounts - SEA) e as Contas Ambientais 5 .

As informações aqui utilizadas são provenientes da base de dados da SEA em sua versão mais recente ("November 2016 Release", lançada em fevereiro de 2018), a qual congrega um conjunto de variáveis econômicas para 43 países (que respondem a mais de $85 \%$ do PIB mundial) e 56 atividades (de acordo com a classificação internacional ISIC Rev. $4^{6}$, a dois dígitos) ao longo do período 2000-2014 ${ }^{7}$.

Para o cálculo da produtividade do trabalho utilizou-se a razão entre o valor adicionado e o pessoal ocupado. As referidas variáveis monetárias estão disponíveis em valores correntes a preços básicos em moeda nacional. Contudo, a SEA também dispõe de séries de índices de volume e de preço (também em moeda nacional) para essas variáveis monetárias, possibilitando, assim, a conversão para valores reais.

Como se pretende trabalhar com comparações ao longo do tempo dos níveis de produtividade setorial entre países (e dentro de agregações setoriais específicas), faz-se necessário corrigir os diferentes níveis de preços dos setores dentro de cada um desses países, pois, caso contrário, afetaria significativamente as análises comparativas dos níveis e das variações dos diferenciais de produtividade entre os países ${ }^{8}$. Essa correção é feita com base nos valores das paridades do poder de compra (purchasing power parity - PPP) setoriais de Inklaar e Timmer (2014), as quais apresentam correspondência com os 35 setores e com quase todos os 43 países (exceções feitas à Croácia, Noruega, Suíça e Taiwan) da SEA/WIOD 2014. A partir dessas séries, utilizou-se da correspondência entre a ISIC Rev.3.1 com a ISIC Rev.4 (ao nível de dois dígitos) para que se dispusesse de valores PPP para todas as 56 atividades da SEA/WIOD 2016.

Para expressar os valores correntes nominais a preços básicos em valores constantes internacionais escolheu-se o ano de 2005 (ano referência para o cálculo dos PPPs setoriais) como base. Nesse sentido, primeiramente, o valor nominal em moeda nacional do valor adicionado (VA) de 2005 foi convertido para dólar a partir da taxa de câmbio do referido ano disponível na Penn World Table 9.0 (FEENSTRA, INKLAAR e TIMMER, 2015) e corrigido pelo índice PPP. Posteriormente, extrapolou-se/retropolou-se esse valor para os demais anos usando a taxa de crescimento real acumulada em 2005 do VA (em moeda nacional), a partir da série de preço do VA. Esse procedimento foi feito para cada um dos setores de cada um dos países da base de dados. Finalmente, as séries de produtividade setorial resultam da razão entre o VA a preços constantes internacionais de 2005 e o pessoal ocupado.

A produtividade do trabalho agregada $(P)$ pode ser apresentada como a soma das produtividades setoriais $(p)$ ponderadas pela participação de cada atividade no emprego total da economia $(s)$. Formalmente:

\footnotetext{
${ }^{5}$ Maiores detalhes podem ser obtidos em Dietzenbacher et al. (2013).

${ }^{6}$ A Classificação Nacional de Atividades Econômicas em sua versão 2.0 (CNAE 2.0) é compatível com a quarta versão da International Standard Industrial Classification of All Economic Activities (ISIC).

${ }^{7}$ Essa última versão aprimora a metodologia da base anterior (SEA/WIOD Update, released July 2014), que disponibiliza informações de 40 países, em um período um pouco maior (1995-2009), mas em uma desagregação setorial inferior (35 atividades, de acordo com a ISIC Rev.3.1, a dois dígitos). Em relação à desagregação setorial, a WIOD 2016 amplia, sobretudo, a abertura da indústria de transformação e dos serviços tradables, destacando, assim, a heterogeneidade que existe dentro dessas atividades, o que é particularmente relevante para os exercícios aqui propostos. Por se tratar de um projeto financiado pela Comissão Europeia, a maioria dos países na base de dados é da Europa. Entretanto, a base de dados também compreende algumas economias da América Latina, América do Norte, Ásia e Oceania, em geral, aquelas mais representativas e com sistemas estatísticos mais consolidados.

${ }^{8}$ Sobretudo, entre países com níveis diferentes de desenvolvimento. Independente do nível de desenvolvimento de uma economia, existem grandes diferenças internas de preços, sobretudo entre os setores tradables e non-tradables. Nesse contexto, emerge o problema de se utilizar a taxa de câmbio agregada para a conversão de certos valores. A referida regularidade empírica ficou conhecida na literatura como "Penn effect", identificada como "Harrod-Balassa-Samuelson effect" nos modelos tradicionais de comércio internacional.
} 


$$
P_{t}^{j}=\frac{Y_{t}^{j}}{L_{t}^{j}}=\frac{\sum_{i} Y_{t}^{j}}{\sum_{i} L_{t}^{j}}=\sum_{i}\left(\frac{Y_{i, t}^{j}}{L_{i, t}^{j}} \frac{L_{i, t}^{j}}{L_{t}^{j}}\right)=\sum_{i} p_{i . t}^{j} s_{i, t}^{j}
$$

onde $Y$ refere-se ao valor adicionado e $L$ ao emprego da atividade da atividade $i$ do país $j$ no tempo $t$.

A partir desse contexto, é possível realizar duas estimativas de como a produtividade agregada do Brasil seria caso ele apresentasse um padrão de produção diferente do, de fato, registrado ao longo do tempo, com base no padrão de produção de outras economias. O primeiro exercício (equação 2) consiste no recálculo da produtividade agregada do Brasil supondo as produtividades setoriais brasileiras, mas substituindo a estrutura de emprego do Brasil por aquela do país $X$. O segundo exercício (equação 3), por outro lado, preserva a estrutura de emprego do Brasil e modifica a produtividade setorial pela de outro país.

$$
\begin{aligned}
& P_{t}^{B R A .1}=\sum_{i} p_{i, t}^{B R A} s_{i, t}^{X} \\
& P_{t}^{B R A .2}=\sum_{i} p_{i, t}^{X} s_{i, t}^{B R A}
\end{aligned}
$$

Nesses termos, o objetivo desses exercícios é estimar o nível que teria a produtividade agregada brasileira caso suas atividades econômicas contassem com os níveis de produtividade das atividades de outros países, ou caso apresentasse uma estrutura de alocação do emprego de outras economias. O primeiro contrafactual permite identificar os ganhos (ou perdas) de produtividade caso a economia brasileira passasse por mudanças intrassetoriais e apresentasse, ceteris paribus, os níveis de produtividade (isto é, decorrente de um diferente ambiente macroeconômico e microeconômico) de uma outra economia. O segundo contrafactual permite inferir os ganhos (ou perdas) de produtividade caso o Brasil passasse, ceteris paribus, por um processo de mudança estrutural (decorrente de modificações na participação do emprego entre as atividades econômicas) como o efetivamente ocorrido em outra economia.

Ressalta-se que os cálculos são feitos para diferentes níveis de agregação setorial e não apenas para o agregado da economia. Assim, além da substituição de cada um dos componentes (estrutura de empregos e produtividade setorial) dentro do cálculo da produtividade agregada do Brasil (isto é, da economia como um todo), também é feito o mesmo exercício para as seguintes agregações setoriais: agropecuária, indústria (também a dividindo entre a indústria de transformação e as outras indústrias), serviços (também o dividindo entre os serviços tradicionais e os serviços modernos) e dividindo a economia em dois setores, o tradicional e o moderno. O recálculo das produtividades setoriais, então, são feitos entre as 3 atividades da agropecuária, as 24 da indústria (19 da indústria de transformação e 5 das outras indústrias), as 29 dos serviços (12 dos serviços tradicionais e 17 dos serviços modernos), as 15 do setor tradicional, as 41 do setor moderno e entre as 56 atividades da economia como um todo. A Tabela 1

\begin{tabular}{|c|c|c|c|}
\hline Atividades WIOD 2016 & Macrossetor desagregado & Economia dual & Macrossetor \\
\hline $\mathrm{A} 01, \mathrm{~A} 02, \mathrm{~A} 03$ & Agropecuária & Setor tradicional & Agropecuária \\
\hline $\mathrm{B}$ & Outras indústrias & \multirow{3}{*}{ Setor moderno } & \multirow{3}{*}{ Indústria } \\
\hline $\begin{array}{c}\mathrm{C} 10-\mathrm{C} 12, \mathrm{C} 13-\mathrm{C} 15, \mathrm{C} 16, \mathrm{C} 17, \mathrm{C} 18, \mathrm{C} 19, \\
\mathrm{C} 20, \mathrm{C} 21, \mathrm{C} 22, \mathrm{C} 23, \mathrm{C} 24, \mathrm{C} 25, \mathrm{C} 26, \mathrm{C} 27, \\
\mathrm{C} 28, \mathrm{C} 29, \mathrm{C} 30, \mathrm{C} 31-\mathrm{C} 32, \mathrm{C} 33\end{array}$ & Indústria de transformação & & \\
\hline D35, E36, E37-E3 & Outras indústrias & & \\
\hline G45, G46, G47 & Serviços tradicionais & Setor tradicional & \multirow{3}{*}{ Serviços } \\
\hline H49, H50, H51, H52, H53 & Serviços modernos & Setor moderno & \\
\hline I & Serviços tradicionais & Setor tradicional & \\
\hline
\end{tabular}
exibe as correspondências entre as atividades econômicas e tais agregações setoriais.

Tabela 1 - Correspondência entre os setores da WIOD 2016 e as agregações utilizadas 


\begin{tabular}{c|c|c|} 
J58, J59-J60, J61, J62-J63, K64, K65, K66 & Serviços modernos & Setor moderno \\
\hline L68 & Serviços tradicionais & Setor tradicional \\
\hline M69-M70, M71, M72, M73, M74-M75 & Serviços modernos & Setor moderno \\
\hline N, O84, P85, Q, R-S, T, U & Serviços tradicionais & Setor tradicional \\
\hline
\end{tabular}

Fonte: Elaboração própria.

Por questões metodológicas, a base final utilizada abrange 55 atividades e 39 países, indicados na Tabela 2.

Tabela 2 - Países analisados

\begin{tabular}{|c|c|c|c|c|c|}
\hline Cód. & País & Continente & Cód. & País & Continente \\
\hline CAN & Canadá & América do Norte & FRA & França & Europa \\
\hline USA & Estados Unidos & América do Norte & GRC & Grécia & Europa \\
\hline BRA & Brasil & América Latina & NLD & Holanda & Europa \\
\hline MEX & México & América Latina & HUN & Hungria & Europa \\
\hline $\mathrm{CHN}$ & China & Ásia & IRL & Irlanda & Europa \\
\hline KOR & Coreia do Sul & Ásia & ITA & Itália & Europa \\
\hline IND & Índia & Ásia & LVA & Letônia & Europa \\
\hline IDN & Indonésia & Ásia & LTU & Lituânia & Europa \\
\hline JPN & Japão & Ásia & LUX & Luxemburgo & Europa \\
\hline DEU & Alemanha & Europa & MLT & Malta & Europa \\
\hline AUT & Áustria & Europa & POL & Polônia & Europa \\
\hline BEL & Bélgica & Europa & PRT & Portugal & Europa \\
\hline BGR & Bulgária & Europa & GBR & Reino Unido & Europa \\
\hline CYP & Chipre & Europa & $\mathrm{CZE}$ & República Tcheca & Europa \\
\hline DNK & Dinamarca & Europa & ROU & Romênia & Europa \\
\hline SVK & Eslováquia & Europa & SWE & Suécia & Europa \\
\hline SVN & Eslovênia & Europa & AUS & Austrália & Oceania \\
\hline ESP & Espanha & Europa & RUS & Rússia & \\
\hline EST & Estônia & Europa & TUR & Turquia & \\
\hline FIN & Finlândia & Europa & & & \\
\hline
\end{tabular}

\section{RESULTADOS}

Nessa seção apresentam-se, em um primeiro momento, os dados gerais da base utilizada, sobretudo aqueles referentes às produtividades agregada e setorial das economias. Destaca-se, ao longo, da seção, a heterogeneidade produtiva entre os países e dentro de cada um deles a partir de uma abordagem multissetorial. $\mathrm{O}$ intuito é fornecer uma melhor compreensão das semelhanças e diferenças entre os padrões da produtividade tanto em relação ao seu nível quanto à sua evolução ao longo do período 2000-2014 para balizar os posteriores exercícios de produtividade cruzada. Por questões de espaço, certas informações apresentadas na subseção 3.1 referem-se apenas a algumas economias selecionadas, obedecendo ao critério de elencar aquelas que representassem diferentes graus de desenvolvimento e regiões geográficas. As análises ao longo da subseção 3.1, todavia, podem abranger todas as economias da base de dados, o que é feito na subseção 3.2.

\subsection{Uma visão geral dos dados}

A Tabela 3 expõe a evolução da participação do emprego em diferentes agregações setoriais para alguns países selecionados da base de dados ${ }^{9}$. Entre 2000 e 2014 a agropecuária no Brasil viu reduzir a sua participação em detrimento da elevação na indústria e nos serviços. Enquanto tal proporção reduziu ligeiramente na indústria de transformação (-0,9 p.p.) e nos serviços modernos (-0,4 p.p.), as outras indústrias e, sobretudo, os serviços tradicionais elevaram sua participação na economia (+2,5 p.p. e $+5,7$ p.p., respectivamente). A despeito da redução da participação do emprego da agropecuária no Brasil no período, a proporção de emprego no setor é ainda bastante elevada quando se compara com os países

\footnotetext{
${ }^{9}$ As análises ao longo do texto, todavia, abrangem todas as economias da base de dados. Em geral, o mesmo padrão é adotado nas demais tabelas e gráficos no decorrer do trabalho.
} 
mais desenvolvidos. Entretanto, a proporção brasileira é inferior à observada na Índia, Indonésia, Romênia, China, México, Bulgária e Rússia. Em relação à indústria, a pequena elevação da participação do emprego no Brasil destoou das demais economias, na medida em que apenas outras sete também apresentaram evolução positiva (Canadá, Indonésia, Romênia, China, Índia, Polônia e Turquia). Entretanto, enquanto as quatro últimas economias referenciadas aumentaram sua proporção do emprego tanto na indústria de transformação quanto nas outras indústrias, as demais economias (incluindo o Brasil) viram apenas a participação das outras indústrias aumentar. Quanto ao nível, o do Brasil foi semelhante à media dos países em 2014. No que se refere aos serviços - o setor mais preponderante em todas as economias ${ }^{10}$ - o Brasil viu aumentar a proporção dos serviços tradicionais e reduzir a proporção dos serviços tradicionais, enquanto que, na média da base de dados, houve incremento dos dois segmentos. A alocação brasileira do emprego nos serviços, apesar de bastante representativa, é ainda bem inferior ao nível observado nos países mais desenvolvidos. Quando se divide a economia em dois setores (o tradicional e o moderno) as proporções brasileiras são similares às dos Estados Unidos, embora a do setor tradicional seja maior do que a média dos demais países e a do setor moderna menor.

Tabela 3 - Alocação do emprego (\%) por diferentes agregações setoriais em 2000 e 2014

\begin{tabular}{|c|c|c|c|c|c|c|c|c|c|c|c|c|c|c|c|c|c|c|}
\hline \multirow{3}{*}{ País } & \multirow{2}{*}{\multicolumn{2}{|c|}{ Agropecuária }} & \multicolumn{6}{|c|}{ Indústria } & \multicolumn{6}{|c|}{ Serviços } & \multirow{2}{*}{\multicolumn{2}{|c|}{$\begin{array}{c}\text { Setor } \\
\text { Tradicional }\end{array}$}} & \multirow{2}{*}{\multicolumn{2}{|c|}{$\begin{array}{c}\text { Setor } \\
\text { Moderno }\end{array}$}} \\
\hline & & & \multicolumn{2}{|c|}{ Total } & \multicolumn{2}{|c|}{ Transformação } & \multicolumn{2}{|c|}{ Outras } & \multicolumn{2}{|c|}{ Total } & \multicolumn{2}{|c|}{ Tradicionais } & \multicolumn{2}{|c|}{ Modernos } & & & & \\
\hline & 2000 & 2014 & 2000 & 2014 & 2000 & 2014 & 2000 & 2014 & 2000 & 2014 & 2000 & 2014 & 2000 & 2014 & 2000 & 2014 & 2000 & 2014 \\
\hline AUS & 4,7 & 2,5 & 20,6 & 19,6 & 11,6 & 7,7 & 9,0 & 11,9 & 74,7 & 77,9 & 56,7 & 59,4 & 18,1 & 18,5 & 61,3 & 61,9 & 38,7 & 38,1 \\
\hline BRA & 20,4 & 13,5 & 20,2 & 21,8 & 12,3 & 11,4 & 1,8 & 10,3 & 59,4 & 64,7 & 49,4 & 55,1 & 10,0 & 9,6 & 69,8 & 68,6 & 30,2 & 31,4 \\
\hline $\mathrm{CHN}$ & 45,7 & 23,8 & 24,0 & 30,6 & 15,3 & 19,6 & 8,6 & 11,0 & 30,4 & 45,6 & 25,9 & 38,0 & 4,5 & 7,6 & 71,6 & 61,8 & 28,4 & 38,2 \\
\hline DNK & 3,4 & 2,6 & 22,0 & 17,2 & 14,6 & 10,3 & 7,5 & 6,9 & 74,6 & 80,2 & 58,8 & 63,3 & 15,8 & 16,9 & 62,2 & 65,9 & 37,8 & 34,1 \\
\hline GBR & 1,3 & 1,4 & 21,6 & 15,8 & 13,8 & 8,1 & 7,8 & 7,7 & 77,1 & 82,8 & 57,9 & 62,8 & 19,2 & 20,1 & 59,2 & 64,1 & 40,8 & 35,9 \\
\hline IND & 59,3 & 44,8 & 16,3 & 22,5 & 11,0 & 12,8 & 5,3 & 9,7 & 24,4 & 32,7 & 19,6 & 25,3 & 4,9 & 7,4 & 78,8 & 70,1 & 21,2 & 29,9 \\
\hline KOR & 11,6 & 5,8 & 26,5 & 22,4 & 18,5 & 15,2 & 8,0 & 7,3 & 61,9 & 71,7 & 46,8 & 53,1 & 15,1 & 18,6 & 58,4 & 59,0 & 41,6 & 41,0 \\
\hline MEX & 18,9 & 18,2 & 31,8 & 28,5 & 16,3 & 12,9 & 15,4 & 15,6 & 49,3 & 53,3 & 40,9 & 44,8 & 8,4 & 8,4 & 59,8 & 63,1 & 40,2 & 36,9 \\
\hline RUS & 25,5 & 15,9 & 25,7 & 23,7 & 15,6 & 12,1 & 10,0 & 11,5 & 48,8 & 60,4 & 41,5 & 52,1 & 7,3 & 8,3 & 67,0 & 68,0 & 33,0 & 32,0 \\
\hline USA & 1,5 & 1,5 & 18,7 & 14,5 & 11,9 & 8,3 & 6,7 & 6,1 & 79,8 & 84,1 & 63,4 & 67,2 & 16,4 & 16,8 & 65,0 & 68,7 & 35,0 & 31,3 \\
\hline $\begin{array}{l}\text { Média } \\
\text { SEA }\end{array}$ & 13,2 & 9,0 & 26,1 & 22,6 & 17,2 & 14,0 & 9,0 & 8,7 & 60,7 & 68,4 & 46,9 & 52,6 & 13,8 & 15,8 & 60,0 & 61,6 & 40,0 & 38,4 \\
\hline
\end{tabular}

Nota: A média SEA exclui o Brasil.

Já na Tabela 4 estão expostos dados sobre o nível de produtividade setorial das economias. Em relação ao Brasil, a agropecuária é o setor menos produtivo, apesar de um crescimento elevado entre 2000 e 2014. Tanto a indústria quanto os serviços apresentam níveis de produtividade semelhantes. Ademais, apesar da produtividade dos serviços modernos brasileiros ser maior do que a dos serviços tradicionais, o nível de produtividade dos serviços modernos brasileiros é bastante inferior ao dos serviços tradicionais de outras economias. Nesse tocante, em praticamente todas as agregações setoriais, a produtividade brasileira se configura como uma das menores em todos os anos dentre as economias abarcadas na base de dados.

Tabela 4 - Produtividade (US\$ 1.000 PPP 2005) por diferentes agregações setoriais em 2000 e 2014

\begin{tabular}{|c|c|c|c|c|c|c|c|c|c|c|c|c|c|c|c|c|c|c|}
\hline \multirow{3}{*}{ País } & \multirow{2}{*}{\multicolumn{2}{|c|}{ Agropecuária }} & \multicolumn{6}{|c|}{ Indústria } & \multicolumn{6}{|c|}{ Serviços } & \multirow{2}{*}{\multicolumn{2}{|c|}{$\begin{array}{c}\text { Setor } \\
\text { Tradicional }\end{array}$}} & \multirow{2}{*}{\multicolumn{2}{|c|}{$\begin{array}{c}\text { Setor } \\
\text { Moderno }\end{array}$}} \\
\hline & & & \multicolumn{2}{|c|}{ Total } & \multicolumn{2}{|c|}{ Transformação } & \multicolumn{2}{|c|}{ Outras } & \multicolumn{2}{|c|}{ Total } & \multicolumn{2}{|c|}{ Tradicionais } & \multicolumn{2}{|c|}{ Modernos } & & & & \\
\hline & 2000 & 2014 & 2000 & 2014 & 2000 & 2014 & 2000 & 2014 & 2000 & 2014 & 2000 & 2014 & 2000 & 2014 & 2000 & 2014 & 2000 & 2014 \\
\hline AUS & 7 & 135 & 108 & 129 & 86 & 99 & 136 & 148 & 1 & 69 & 54 & 61 & 84 & 95 & 5 & 64 & 96 & 112 \\
\hline $\mathrm{BR}$ & & 11 & 19 & 2 & 16 & 20 & 22 & 22 & & 1 & 1 & & & 32 & 11 & 15 & 21 & 24 \\
\hline $\mathrm{CHI}$ & 2 & 4 & 10 & 37 & 9 & 4 & 13 & 24 & 10 & 18 & $\varepsilon$ & 14 & 17 & 3 & 4 & 0 & 11 & 37 \\
\hline DNK & 60 & 84 & 104 & 122 & 100 & 149 & 111 & 83 & 5 & 65 & 53 & 5 & 75 & 108 & 54 & 55 & 2 & 115 \\
\hline GBP & 6 & 59 & 87 & 102 & 82 & 123 & 97 & 81 & 61 & 73 & 5 & 64 & 79 & 100 & 55 & 64 & 83 & 101 \\
\hline IND & 2 & 2 & 7 & 9 & 6 & 9 & 1( & 8 & 14 & 1 & 15 & 1 & 13 & 23 & 5 & 8 & 8 & 12 \\
\hline KOR & 8 & 16 & 77 & 126 & 77 & 142 & 75 & 93 & 43 & 46 & 38 & 38 & 61 & 69 & 32 & 36 & 71 & 100 \\
\hline
\end{tabular}

\footnotetext{
${ }^{10}$ Com exceção, em 2000, na China, Índia e Romênia, e, em 2014, na Índia.
} 


\begin{tabular}{|c|c|c|c|c|c|c|c|c|c|c|c|c|c|c|c|c|c|c|}
\hline MEX & 9 & 9 & 45 & 50 & 46 & 56 & 43 & 46 & 48 & 50 & 44 & 41 & 71 & 103 & 33 & 32 & 50 & 62 \\
\hline RUS & 3 & 5 & 24 & 37 & 17 & 33 & 35 & 41 & 22 & 30 & 20 & 26 & 32 & 55 & 13 & 21 & 26 & 42 \\
\hline USA & 84 & 123 & 120 & 176 & 113 & 192 & 133 & 154 & 73 & 86 & 61 & 70 & 118 & 154 & 62 & 71 & 120 & 164 \\
\hline $\begin{array}{c}\text { Média } \\
\text { SEA }\end{array}$ & 31 & 42 & 58 & 74 & 58 & 82 & 58 & 60 & 50 & 56 & 46 & 49 & 65 & 82 & 42 & 46 & 60 & 77 \\
\hline
\end{tabular}

Nota: A média SEA exclui o Brasil.

Enquanto a tabela anterior expõe os níveis de produtividade setorial em anos selecionados, o Gráfico 1 permite identificar a evolução ao longo dos anos da produtividade agregada do Brasil e de outras economias selecionadas e a distância produtiva do país em relação a essas economias. Em 2014, por exemplo, a produtividade da Turquia foi praticamente o dobro da brasileira $(1,96)$ e a do México mais do que o dobro $(2,45)$. Além do mais, enquanto a produtividade da economia brasileira era mais que o dobro que a da China $(2,25)$ em 2000, esta ultrapassou o nível de produtividade do Brasil em 2012 e ampliou a distância em 2014.

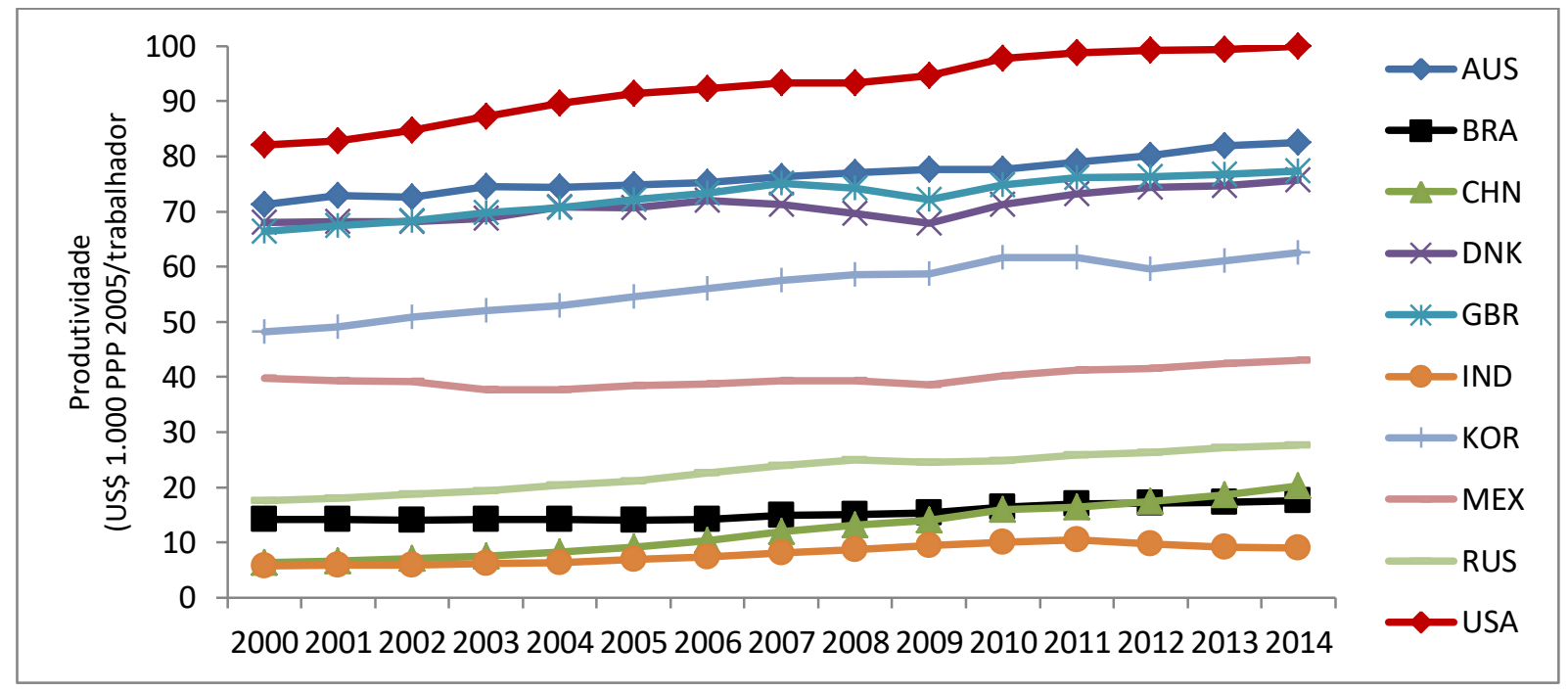

Gráfico 1 - Evolução anual do nível de produtividade de economias selecionadas

Nesse particular, o Gráfico 2 permite identificar o crescimento acumulado da produtividade do Brasil e dos países selecionados. Como se pode observar, a produtividade brasileira ficou estagnada até 2006 (registrando uma ligeira retração acumulada de $-0,1 \%$ ), momento no qual passou a crescer ano após ano, terminando com um crescimento acumulado de $23,9 \%$ no período $2000-2014$, isto é, uma taxa média de crescimento anual de 1,6\%, superior ao desempenho dos Estados Unidos, Japão, México e Itália. Já a economia chinesa registrou um crescimento da produtividade bastante expressivo e destoante de todas as outras economias da base de dados, com um crescimento médio anual de 14,7\% no período. A Índia, apesar de uma redução em sua taxa a partir de 2012, figurou entre as cinco economias com o maior crescimento acumulado da produtividade ${ }^{11}$, seguida pela Rússia. Por outro lado, a Itália registrou uma retração acumulada de $7,0 \%(0,4 \%$ a.a. $)$, a maior entre todos os países ${ }^{12}$.

\footnotetext{
${ }^{11}$ Os maiores crescimentos acumulados da produtividade foram registrados na China $(+14,7 \%$ a.a. $)$, Romênia $(+7,4 \%$ a.a. $)$, Lituânia ( $+5,6 \%$ a.a.), Letônia ( $+4,5 \%$ a.a.) e Índia ( $+3,8 \%$ a.a.).

${ }^{12}$ Luxemburgo foi outro país que também registrou retração acumulada no período 2000-2014 (-0,3\% a.a.). Os outros países com os menores crescimentos acumulados foram, em ordem decrescente, Grécia (-0,2\% a.a.), Finlândia (-0,3\% a.a.) e Áustria $(-0,5 \%$ a.a. $)$.
} 


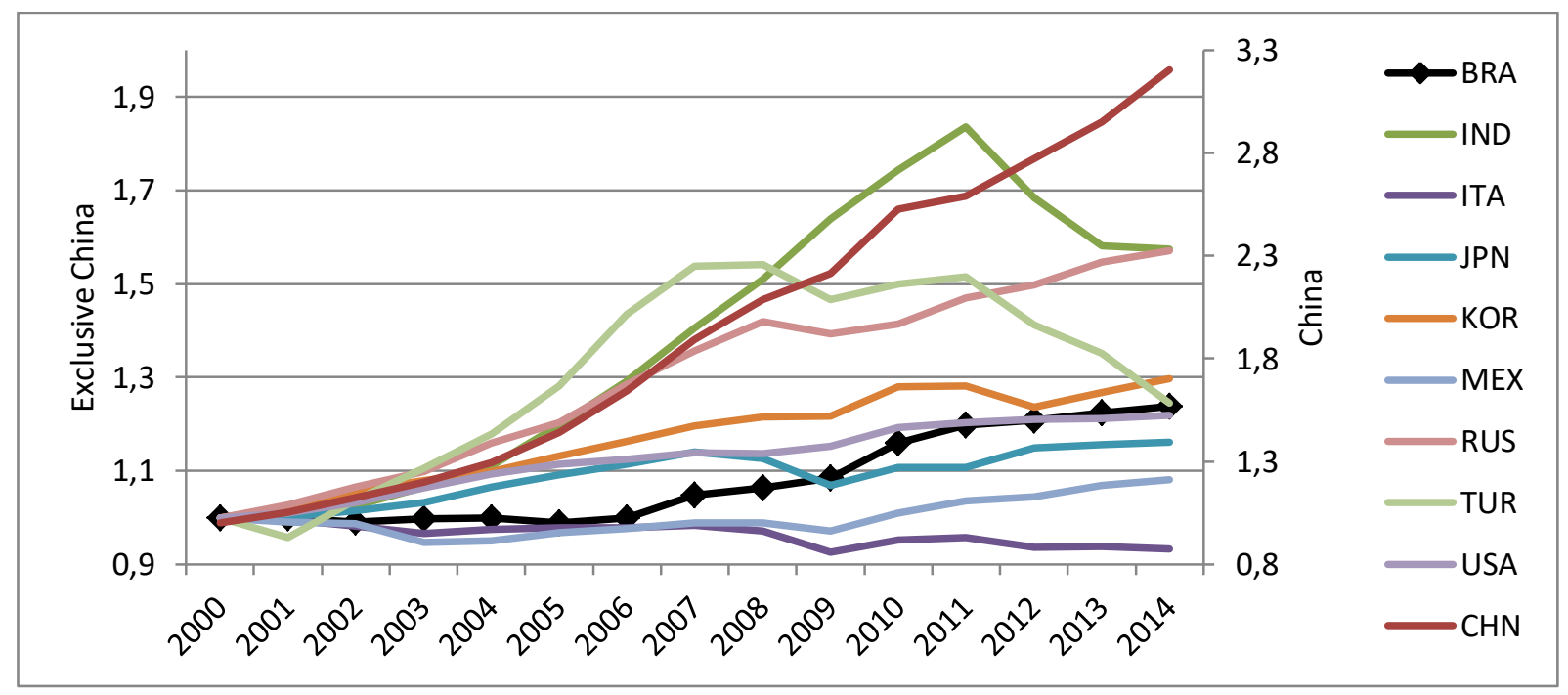

Gráfico 2 - Evolução anual da produtividade de economias selecionadas $(2000=1)$

A Tabela 5 permite avaliar a distância e a evolução da produtividade brasileira em relação aos níveis mais altos e mais baixos de produtividade dos países da base de dados. Em outras palavras, permite verificar se o crescimento registrado da produtividade do Brasil - vista no Gráfico 2 - proporcionou ao país, por um lado, se aproximar da fronteira de produtividade/tecnológica mundial e, por outro, abrir distância frente aos menores níveis de produtividade. Analisando a produtividade agregada da economia (últimas duas linhas da referida tabela) apreende-se que o Brasil reduziu o gap de produtividade em relação à fronteira mundial, ao mesmo tempo em que a economia menos produtiva também reduziu o gap de produtividade em relação ao Brasil. O mesmo comportamento da produtividade agregada foi verificado nas produtividades dos serviços e das outras indústrias. Por outro lado, o Brasil viu reduzir o seu gap em relação à fronteira produtiva mundial e aumentar o sua distância dos países menos produtivos na agropecuária e nos serviços tradicionais. Todavia, enquanto a distância dos dois extremos de produtividade nos serviços tradicionais é relativamente pequena, na agropecuária ela é mais acentuada. Já na indústria, na indústria de transformação, nos serviços modernos e no setor moderno, o Brasil se distanciou da fronteira produtiva ao mesmo tempo em que viu diminuir a distância em relação aos países menos produtivos. Além do mais, esses são, justamente, os setores com o maior potencial de dinamizar a produtividade agregada da economia. Por fim, fica realçado que a distância de produtividade é muito maior entre a fronteira produtiva e o Brasil do que entre o Brasil e os países no piso de produtividade.

Tabela 5 - Relações de produtividade entre o Brasil e as produtividades máximas e mínimas por diferentes agregações setoriais, 2000 e 2014

\begin{tabular}{ccrrrrc}
\hline \multirow{2}{*}{ Setores de atividade } & Relação de produtividade & $\mathbf{2 0 0 0}$ & $\mathbf{2 0 0 5}$ & $\mathbf{2 0 0 9}$ & $\mathbf{2 0 1 4}$ & $\begin{array}{c}\text { Evolução } \\
\mathbf{2 0 0 0 - 2 0 1 4}\end{array}$ \\
& & & & \\
& País mais produtivo/Brasil & 15,7 & 18,1 & 15,9 & 12,2 & Melhorou \\
Agropecuária & Brasil/País menos produtivo & 3,0 & 3,1 & 3,3 & 5,0 & Melhorou \\
\hline \multirow{2}{*}{ Indústria } & País mais produtivo/Brasil & 6,6 & 8,0 & 8,9 & 8,6 & Piorou \\
& Brasil/País menos produtivo & 3,2 & 2,1 & 1,8 & 2,3 & Piorou \\
\hline \multirow{2}{*}{ Serviços } & País mais produtivo/Brasil & 7,5 & 7,4 & 6,8 & 6,8 & Melhorou \\
& Brasil/País menos produtivo & 2,2 & 1,8 & 1,8 & 2,1 & Piorou \\
\hline \multirow{2}{*}{ Indústria de transformação } & País mais produtivo/Brasil & 9,0 & 12,4 & 12,2 & 9,8 & Piorou \\
& Brasil/País menos produtivo & 2,8 & 2,1 & 1,4 & 2,1 & Piorou \\
\hline \multirow{2}{*}{ Outras indústrias } & País mais produtivo/Brasil & 8,2 & 7,8 & 7,0 & 7,4 & Melhorou \\
& Brasil/País menos produtivo & 4,0 & 2,8 & 2,6 & 2,6 & Piorou \\
\hline \multirow{2}{*}{ Serviços tradicionais } & País mais produtivo/Brasil & 6,3 & 5,9 & 5,7 & 5,6 & Melhorou \\
& Brasil/País menos produtivo & 2,1 & 1,8 & 1,8 & 2,2 & Melhorou \\
\hline \multirow{2}{*}{ Serviços modernos } & País mais produtivo/Brasil & 6,7 & 7,2 & 5,9 & 9,3 & Piorou \\
& Brasil/País menos produtivo & 2,5 & 1,9 & 1,6 & 2,0 & Piorou \\
\hline \multirow{2}{*}{ Setor tradicional } & País mais produtivo/Brasil & 7,6 & 6,8 & 6,3 & 5,8 & Melhorou \\
& Brasil/País menos produtivo & 2,6 & 2,2 & 2,2 & 2,7 & Melhorou \\
\hline \multirow{2}{*}{ Setor moderno } & País mais produtivo/Brasil & 6,4 & 7,0 & 7,3 & 9,2 & Piorou
\end{tabular}




\begin{tabular}{ccrrrrc} 
& Brasil/País menos produtivo & 2,6 & 1,9 & 1,6 & 2,0 & Piorou \\
\hline \multirow{2}{*}{ Total da economia } & País mais produtivo/Brasil & 7,8 & 7,6 & 6,6 & 6,8 & Melhorou \\
& Brasil/País menos produtivo & 2,5 & 2,0 & 1,8 & 2,2 & Piorou \\
\hline
\end{tabular}

Os dados expostos até agora trataram de apresentar um panorama sobre a estrutura de empregos e a produtividade setorial das economias ao longo do período 2000-2014. O intuito foi o de trazer algumas informações para balizar os exercícios de produtividade cruzada, os quais estão expostos na próxima subseção.

\subsection{Resultados contrafactuais}

Nessa subseção apresentam-se os resultados obtidos das estimações das produtividades cruzadas do Brasil, a partir de razões contrafactuais da produtividade, isto é, a divisão entre o valor da produtividade do Brasil supondo a estrutura de emprego ou a produtividade de outro país pela produtividade brasileira de fato. Valores maiores do que a unidade indicam que a produtividade do Brasil seria maior no caso contrafactual (a produtividade cresceria), enquanto que valores menores do que um indicam que a produtividade oficial do país é maior do que seria a sua produtividade contrafactual.

O Gráfico 3 exibe as razões de produtividade alterando-se tanto a estrutura de emprego (contrafactual 1) quanto a produtividade setorial do Brasil (contrafactual 2) pela de outros países para os anos polares da base de dados. Como pode-se verificar, os ganhos potenciais de produtividade seriam muito maiores no caso em que o Brasil passasse a exibir níveis de produtividade semelhantes aos demais países do que a estrutura de empregos dessas economias.

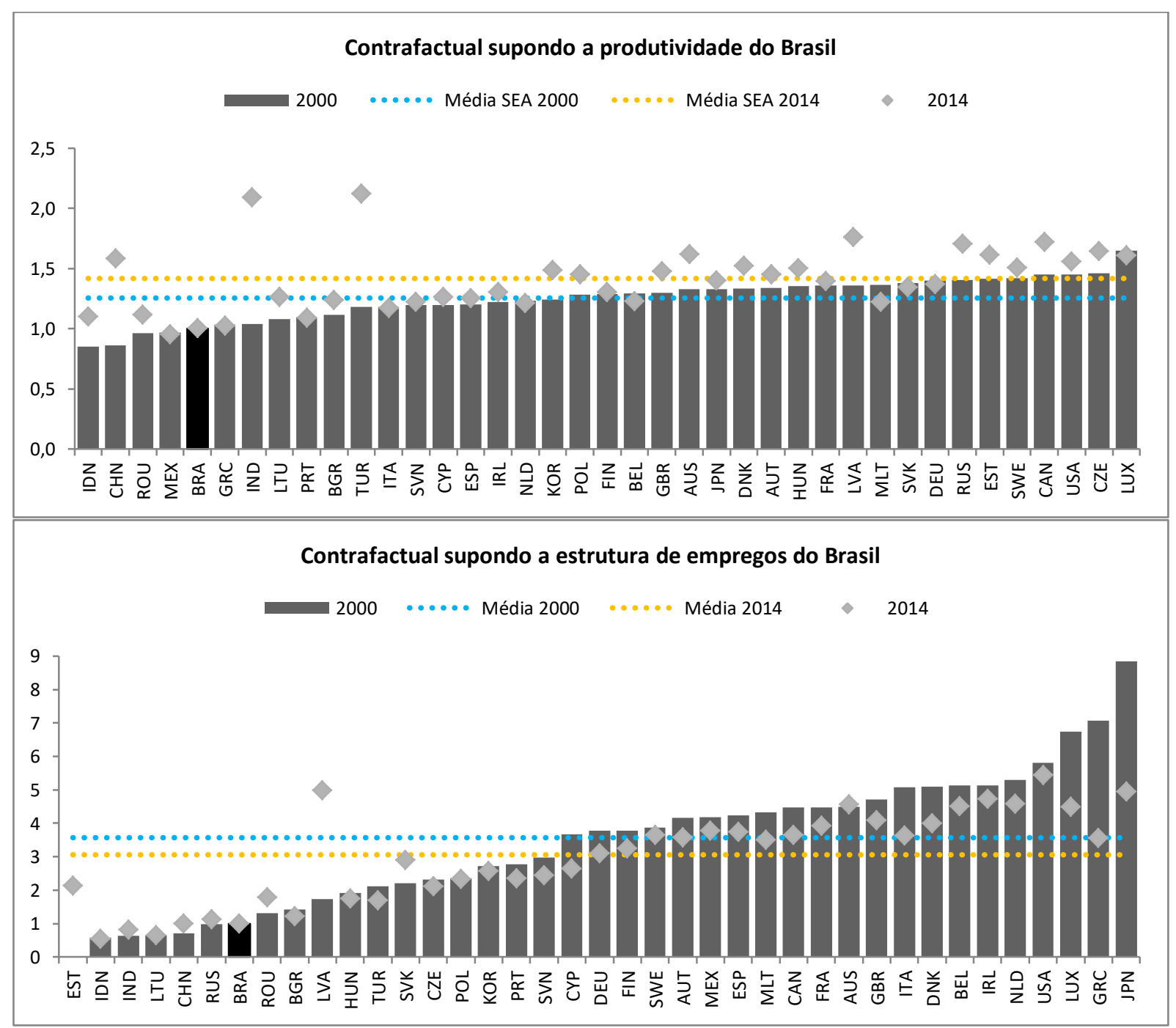

Gráfico 3 - Razões contrafactuais da produtividade agregada do Brasil com países de referência, 2000 e 2014 
Notas: Os valores dos eixos diferem entre os dois gráficos. A média exclui o Brasil.

Em relação à primeira das produtividades cruzadas, a produtividade agregada do Brasil reduziria em 2000 caso a alocação do emprego fosse semelhante à da Indonésia, China, Índia, Romênia e México. Já em 2014, isso aconteceria apenas substituindo a estrutura de empregos pela do México. Por outro lado, caso a proporção do pessoal ocupado em cada atividade econômica fosse igual a de Luxemburgo em 2000, a produtividade brasileira poderia aumentar mais que 1,5 vezes (sobretudo, pela "atividade de serviços financeiros"). Já em 2014, os ganhos de produtividade seriam duas vezes maiores com a estrutura setorial do emprego da Turquia e da Índia (ambos pelas "atividades imobiliárias"). Ademais, na maioria dos casos, o Brasil passaria a registrar uma produtividade mais elevada em 2014 do que em 2000.

No que se refere ao segundo exercício de produtividade cruzada, a produtividade agregada do Brasil em 2000 apenas não seria maior caso suas produtividades setoriais se assemelhassem às da Rússia, China, Lituânia, Indonésia e Índia. Os níveis de produtividade setorial desses mesmos países, com exceção da Rússia, também não aumentariam a produtividade agregada brasileira em 2014 . O caso extremo positivo em 2000 seria com o cruzamento entre a estrutura de ocupações do Brasil e a produtividade das atividades do Japão; nesse caso, os ganhos de produtividade pelo Brasil seriam de 783,9\% (sobretudo pelas atividades "serviços domésticos" e "comércio atacadista"). Já em 2014, o maior ganho seria com os Estados Unidos, 443,9\% (sobretudo pelas atividades "agricultura, pecuária e serviços relacionados" e "comércio atacadista").

Enquanto o Gráfico 3 permite avaliar as razões de produtividade contrafactuais de todos os países apenas em 2000 e 2014, o Gráfico 4 expõe as produtividades contrafactuais do Brasil para todos os anos da série, mas apenas para alguns países de referência, permitindo avaliar as evolução duas produtividades contrafactuais ao longo do tempo.

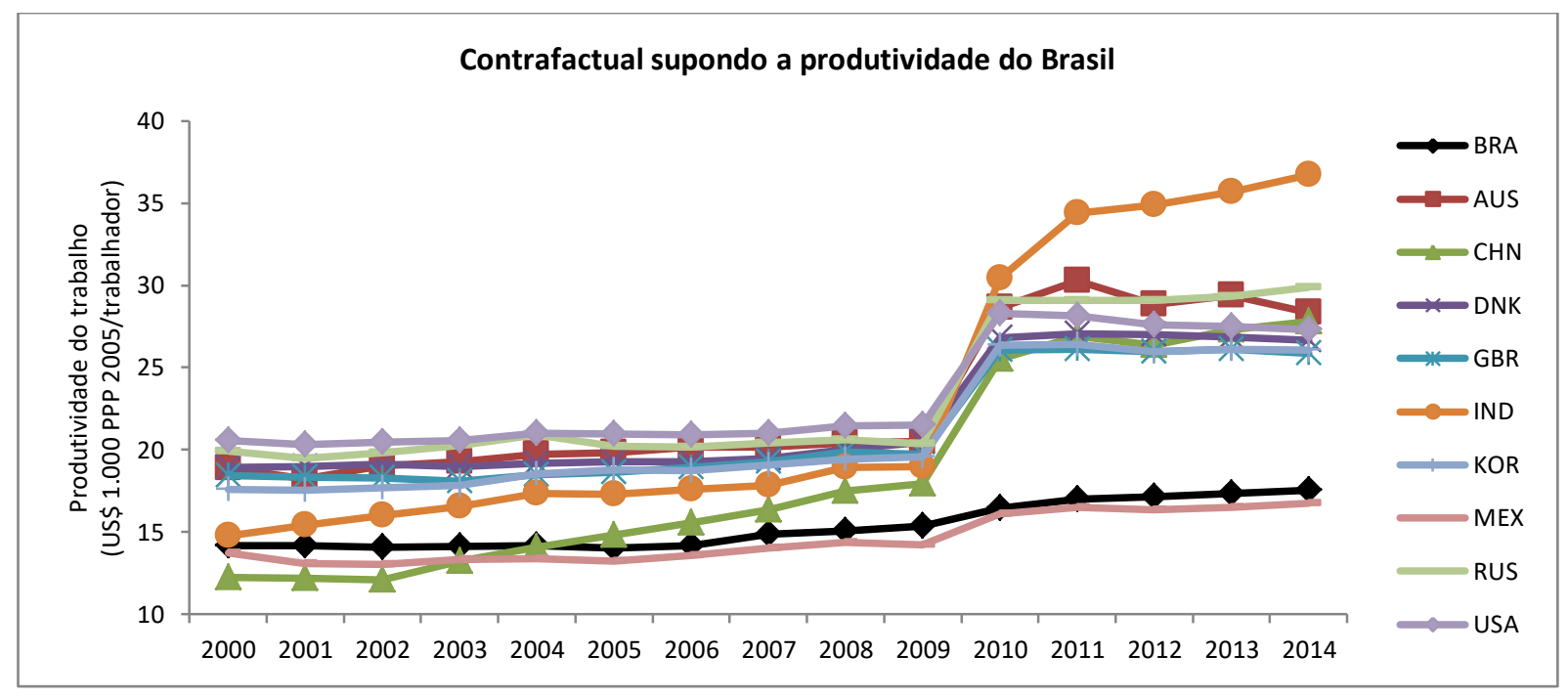




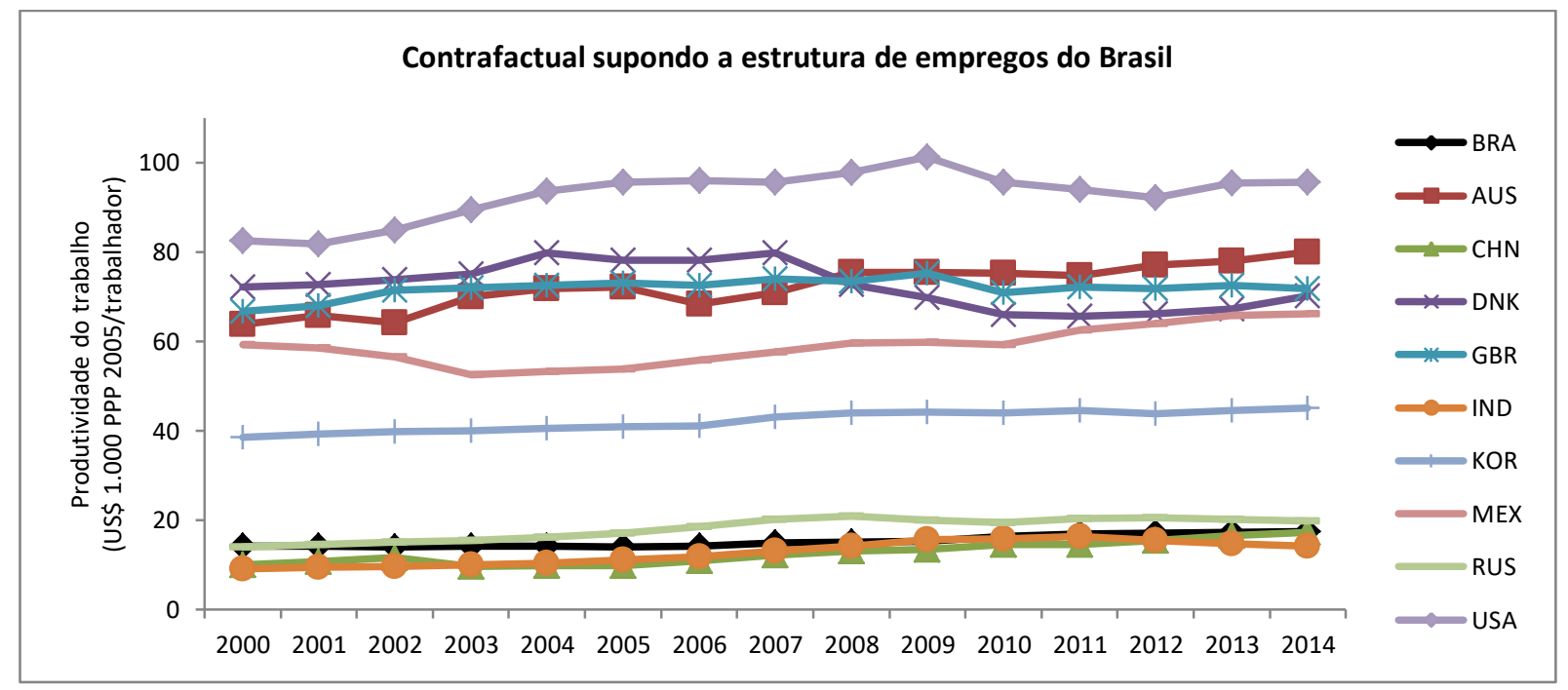

Gráfico 4 - Evolução anual das produtividades contrafactuais para países de referência selecionados

Ampliando a análise para todos os países da base de dados (38 ao total) e todos os anos (2000 a 2014), os únicos casos em que a produtividade do segundo exercício contrafactual não seria maior do que a produtividade oficial brasileira seriam com: China, Indonésia e Lituânia em todos os anos, Índia em todos os anos, com exceção de 2009 e Rússia em 2000. Para todos os outros casos, a produtividade brasileira se elevaria. Apesar de ganhos menores em relação ao segundo exercício contrafactual, o primeiro contrafactual também traria ganhos generalizados para a produtividade brasileira. Os únicos casos em que o Brasil não elevaria sua produtividade agregada seriam: tomando a China como referência de 2000 a 2004, a Grécia em 2009, a Indonésia de 2000 a 2009, o México em todos os anos (2000 a 2014) e a Romênia em 2000 e 2001. Considerando a média dos países da SEA/WIOD 2016, o primeiro exercício contrafactual traria um crescimento médio para a produtividade brasileira no período 2000-2014 de $33 \%$, enquanto o segundo exercício contrafactual traria um crescimento médio de $236 \%$ no mesmo período. Ressalta-se que os ganhos potenciais pelo primeiro contrafactual se elevam após a crise financeira mundial de 2008-2009, enquanto que os seriam obtidos com o segundo contrafactual se reduzem, conforme pode ser verificado no Gráfico 5.

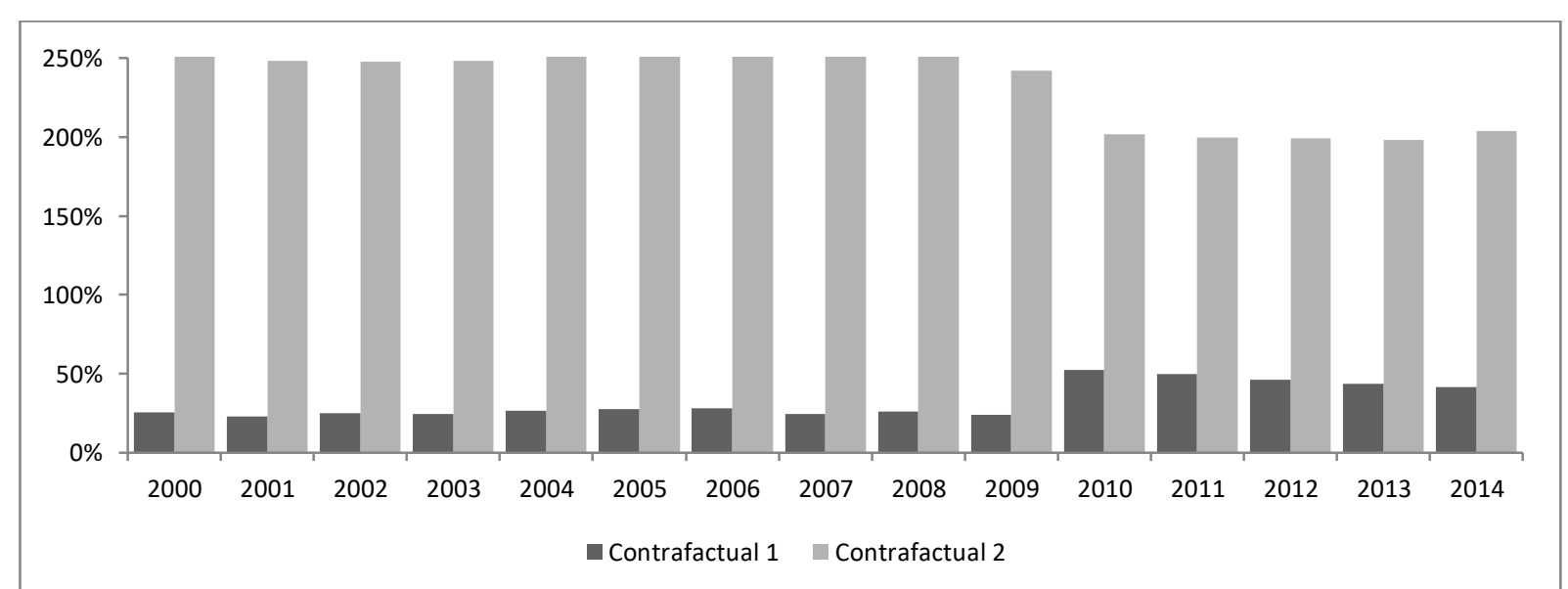

Gráfico 5 - Crescimento contrafactual da produtividade do Brasil em relação à média dos países da SEA/WIOD 2016, 2000 a 2014

Os Gráficos a seguir exibem qual seria o crescimento da produtividade em diferentes agregações setoriais do Brasil em um dado ano de acordo com os dois exercícios de produtividade. Em relação à agropecuária (Gráfico 6), o ganho de produtividade supondo os níveis brasileiros de produtividade setorial seria nulo até 2009. Em 2014 o crescimento seria modesto, chegando a 10\% com os Estados Unidos como referência e a $14 \%$ com a Suécia (crescimento máximo). Por outro lado, o exercício contrafactual indicou retração do crescimento da produtividade da agropecuária com a Austrália (- 
0,03\%), o México (-1\%) e a Rússia (-3\%, o maior recuo entre todos os países da base de dados). Já o crescimento da produtividade da agropecuária a partir do cruzamento da estrutura de empregos do Brasil com as produtividades dos subsetores de outros países seria bastante substancial em todos dos anos. O exercício com os Estados Unidos traria o maior crescimento entre todos os países avaliados, seguido pela Austrália: nos quatro anos expostos na tabela, com ambos os países como referência, a produtividade da agropecuária brasileira cresceria mais de $1.000 \%$. Se a produtividade setorial fosse igual à da média dos países da SEA/WIOD 2016, o aumento de produtividade seria de 462\% em 2000 e de 271\% em 2014. Mais uma vez, o crescimento da produtividade, agora da agropecuária, seria muito mais elevado quando da substituição das produtividades setoriais pelas de outros países do que se o Brasil passasse a apresentar uma alocação do emprego semelhante a desses países.

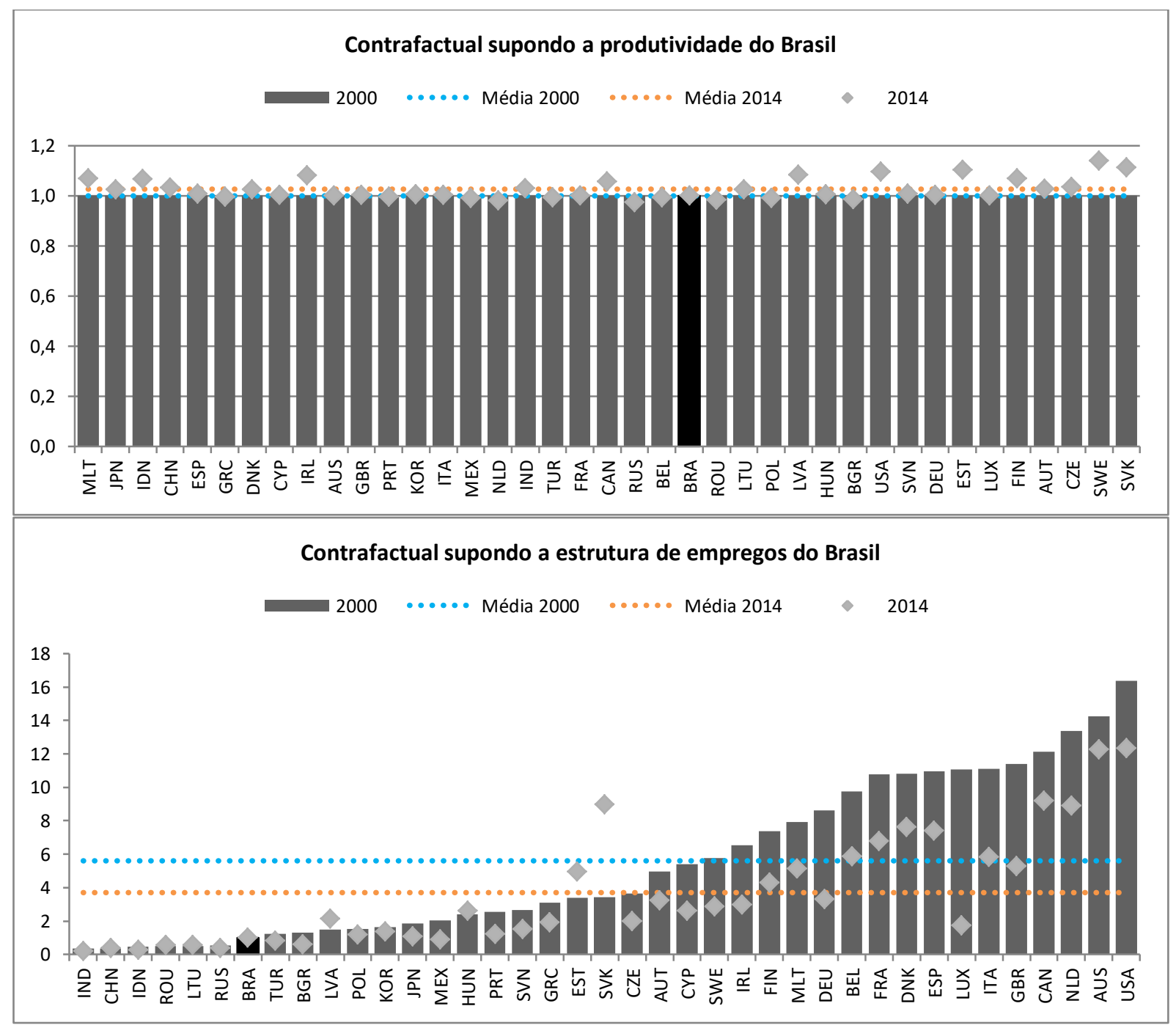

Gráfico 6 - Razões contrafactuais da produtividade da agropecuária do Brasil com países de referência, 2000 e 2014

Notas: Os valores dos eixos diferem entre os dois gráficos. A média exclui o Brasil.

O mesmo padrão seria encontrado para o caso da indústria, tanto em termos agregados (Gráfico 7), quanto em seus subsetores ${ }^{13}$. Haveriam ganhos nos dois exercícios, embora no segundo deles o crescimento potencial seria muito mais elevado. Tomando a média dos países da SEA/WIOD 2016, enquanto que no primeiro contrafactual os ganhos de produtividade da indústria, da indústria de transformação e das outras indústrias em 2014 seriam de $21 \%, 12 \%$ e 37\%, respectivamente, no segundo contrafactual esses valores seriam de $200 \%, 263 \%$ e $137 \%$. Os países de referência que trariam os maiores ganhos produtivos no referido ano para a indústria brasileira seria, no primeiro contrafactual,

\footnotetext{
${ }^{13}$ Por limitação de espaço, os gráficos referentes à indústria de transformação e às outras indústrias não são exibidos.
} 
Rússia (crescimento de 82\%) e, no segundo contrafactual, Estados Unidos (crescimento de 534\%). Já para a indústria de transformação os maiores ganhos viriam da Irlanda (48\%) e Estados Unidos (664\%), respectivamente. Por seu turno, os maiores crescimento para as outras indústrias viriam da Rússia (127\%) e Estados Unidos (404\%). Entre a indústria de transformação e as outras indústrias, os maiores ganhos de produtividade pelo segundo contrafactual viriam da indústria de transformação, o que indica que o maior atraso em termos de produtividade setorial brasileira está nesse segmento. Um resultado interessante é que os ganhos de produtividade do segundo contrafactual tendo a China como referência seriam negativos em 2000 e passariam a ser positivos em 2014 para os três segmentos analisados. De fato, o nível de produtividade industrial chinesa aumentou consistentemente ao longo de todo o período 2000-2014, ultrapassando o nível brasileiro em 2006. Enquanto a China registrou um crescimento médio anual de $9,6 \%$ no período 2000-2014, o crescimento industrial brasileiro foi de $0,8 \%$ a.a. ${ }^{14}$. Em relação à indústria de transformação, a produtividade chinesa ultrapassou a do Brasil em 2005 e nas outras indústrias em 2014.

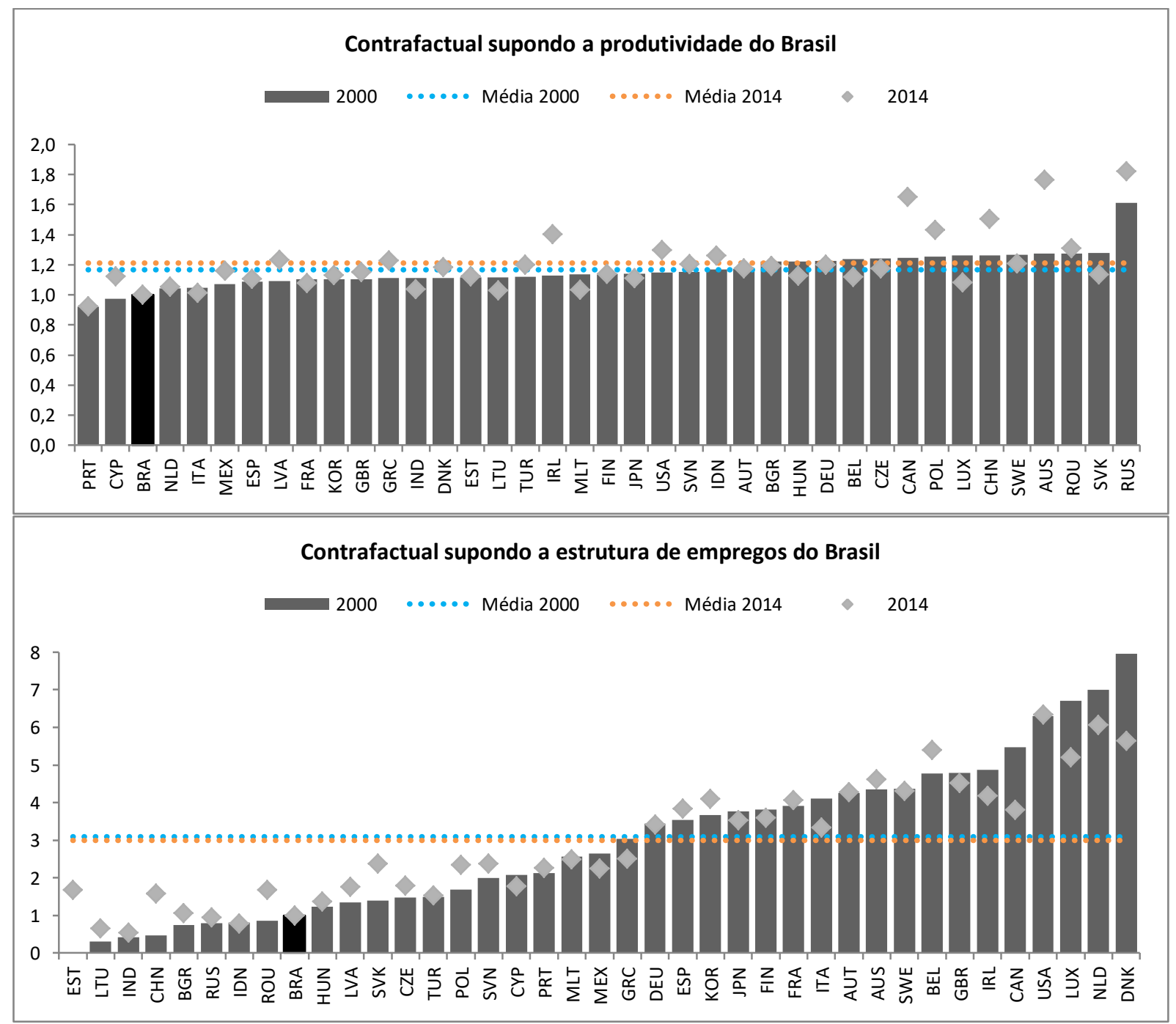

Gráfico 7 - Razões contrafactuais da produtividade da indústria do Brasil com países de referência, 2000 e 2014

Notas: Os valores dos eixos diferem entre os dois gráficos. A média exclui o Brasil.

Passando à análise do exercício de produtividade cruzada para o setor de serviços (Gráfico 8), também observa-se um ganho maior de produtividade do Brasil pelo segundo contrafactual do que pelo

\footnotetext{
${ }^{14} \mathrm{O}$ resultado final positivo foi fruto da elevação do nível de produtividade da indústria a partir de 2009. Entre 2000 e 2008 o crescimento anual média da indústria brasileira foi de $-0,8 \%$.
} 
primeiro para todos os três segmentos para todos os anos ${ }^{15}$. Enquanto o primeiro contrafactual para os serviços tomando a média dos países da base de dados traria um crescimento de $20 \%$ para a produtividade brasileira do setor em 2000 e de $54 \%$ em 2014, o segundo contrafactual traria crescimentos de $245 \%$ e $197 \%$, respectivamente. No caso do primeiro exercício contrafactual, o maior ganho de produtividade do setor de serviços em 2014 seria tomando como referência a estrutura de empregos da China (357\%). Já no caso do segundo contrafactual, o maior ganho adviria dos níveis de produtividade setorial tomando como referência a Letônia (559\%). Em relação à desagregação entre serviços tradicionais e serviços modernos, é interessante notar que, em geral, os ganhos relativos ao setor tradicional seriam maiores do que os do setor moderno nos dois exercícios contrafactuais, indicando, assim, que o maior atraso em termos de produtividade setorial brasileira estaria nos serviços tradicionais relativamente ao setor moderno. Para o caso do primeiro contrafactual, haveria perda de produtividade no setor moderno brasileiro com a maioria dos países identificados na tabela, sobretudo com aqueles com nível mais elevado de renda per capita.

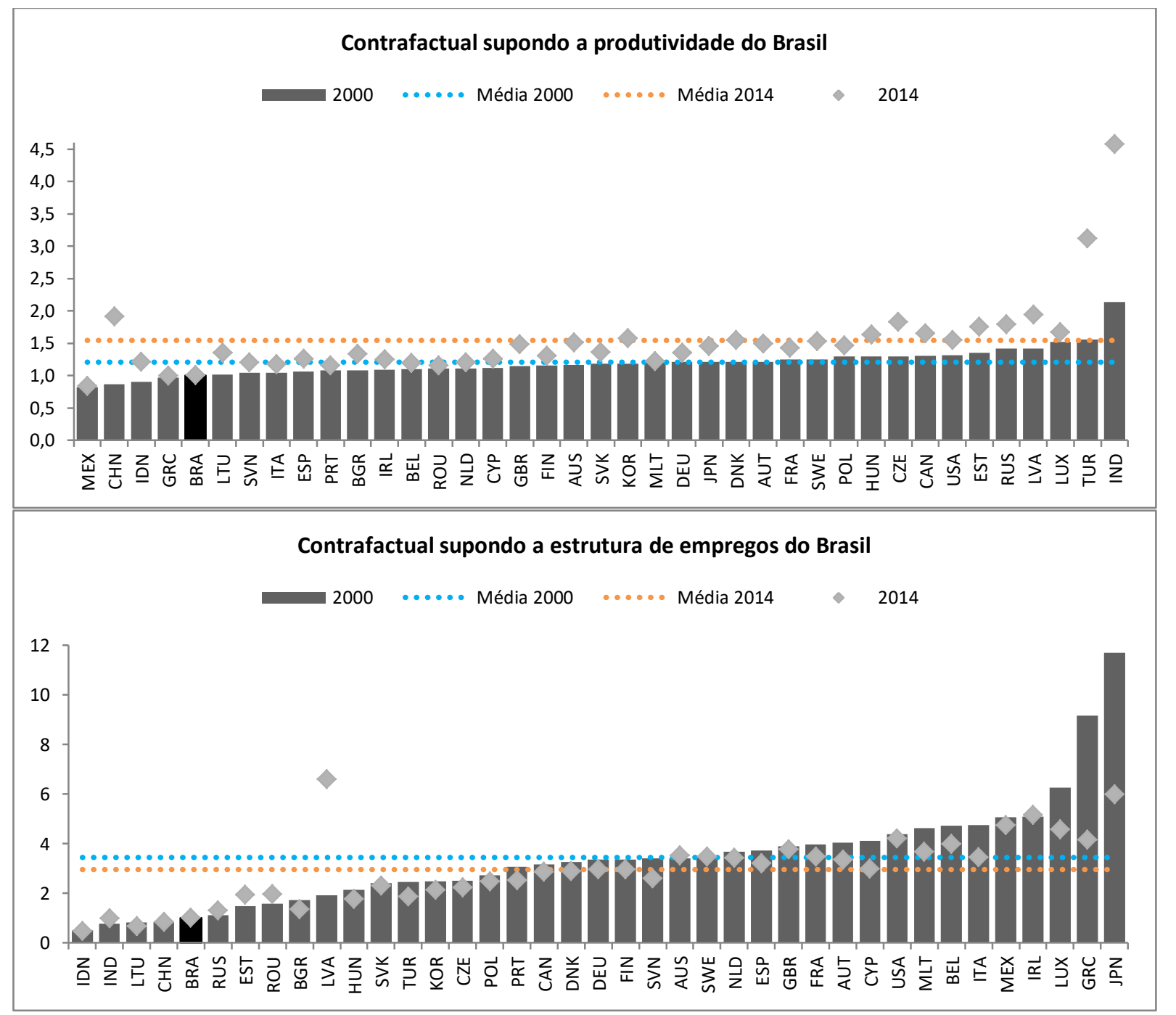

\section{Gráfico 8 - Razões contrafactuais da produtividade dos serviços do Brasil com países de referência, 2000 e 2014}

Notas: Os valores dos eixos diferem entre os dois gráficos. A média exclui o Brasil.

$\mathrm{Na}$ divisão da economia entre dois setores (tradicional, Gráfico 9, e moderno, Gráfico 10) ocorreria o mesmo que entre os serviços tradicionais e modernos: os ganhos em ambos os exercícios contrafactuais seriam maiores para o setor tradicional (62\% e $222 \%$ em 2014, respectivamente) do que para o setor moderno ( $12 \%$ e $188 \%$ em 2014, respectivamente). De qualquer forma, tendo como referência a ampla maioria dos países da base de dados, os ganhos de produtividade para o Brasil seriam

\footnotetext{
${ }^{15}$ Por limitação de espaço, os gráficos referentes aos serviços tradicionais e aos serviços modernos não são exibidos.
} 
elevados, chegando, em 2014, a 194\% (tendo como referência a Turquia) no setor tradicional e 58\% (tendo como referência a Rússia) no setor moderno no primeiro contrafactual e, no segundo contrafactual, a $602 \%$ no setor tradicional (Chipre) e a $485 \%$ no setor moderno (Irlanda).

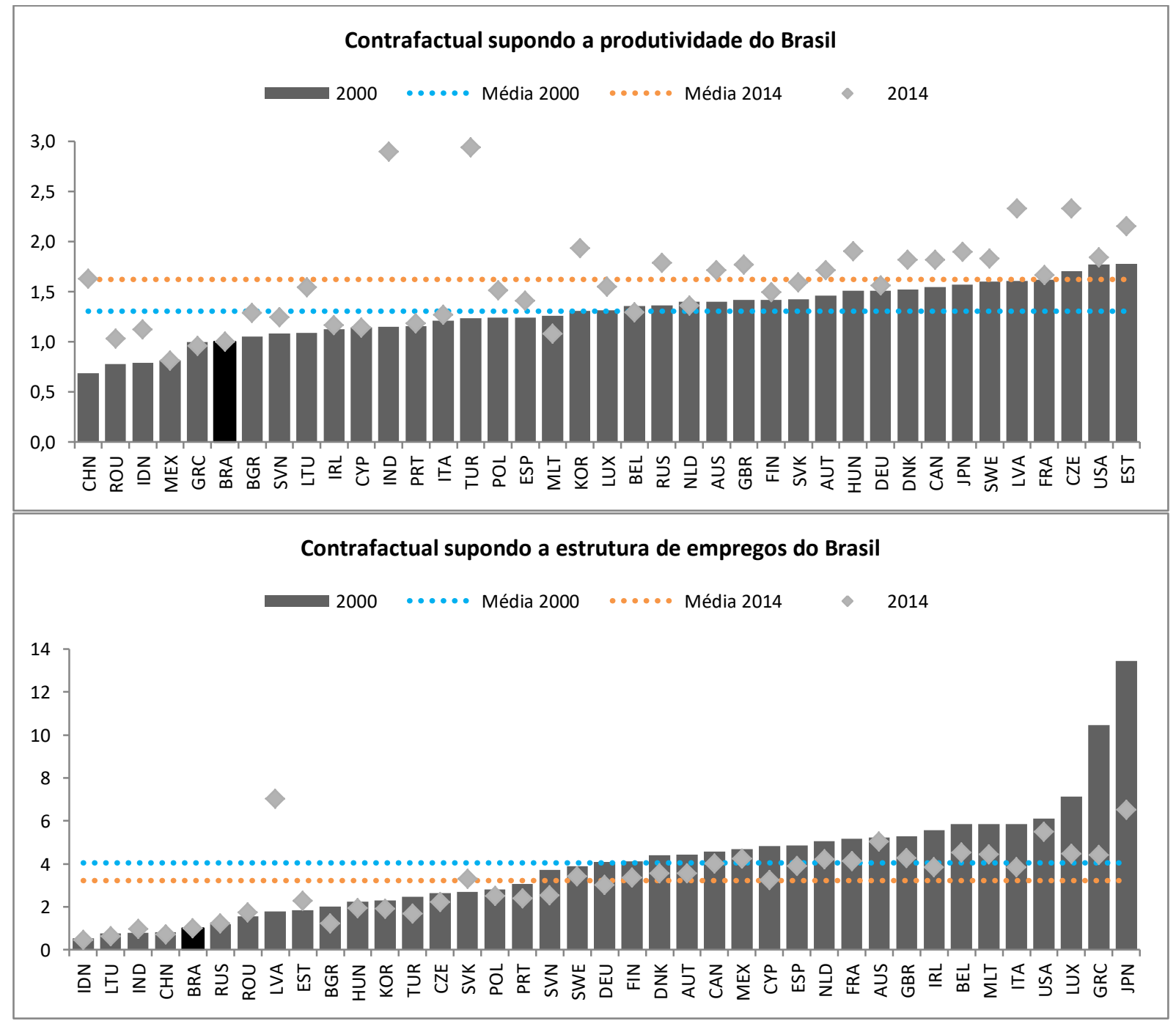

Gráfico 9 - Razões contrafactuais da produtividade do setor tradicional do Brasil com países de referência, 2000 e 2014

Notas: Os valores dos eixos diferem entre os dois gráficos. A média exclui o Brasil.

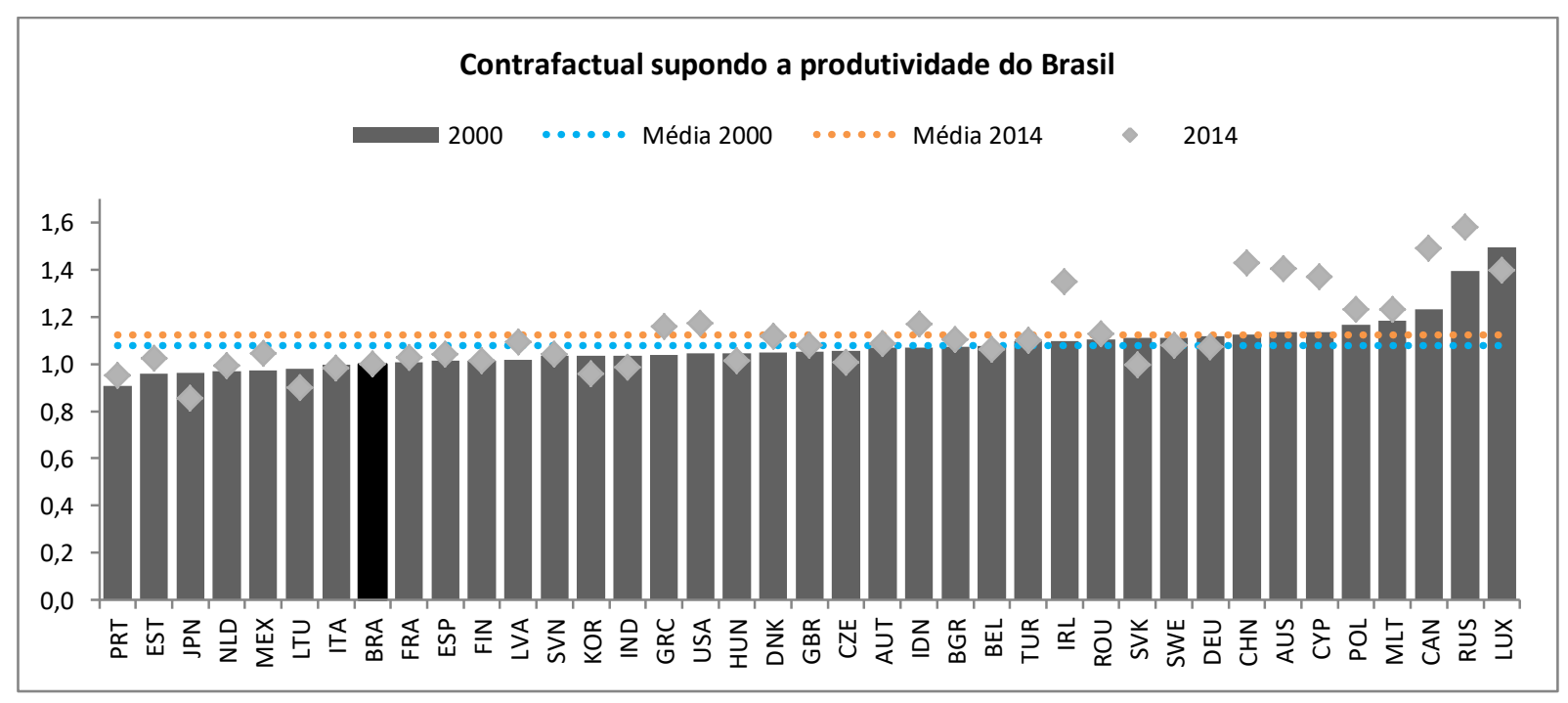




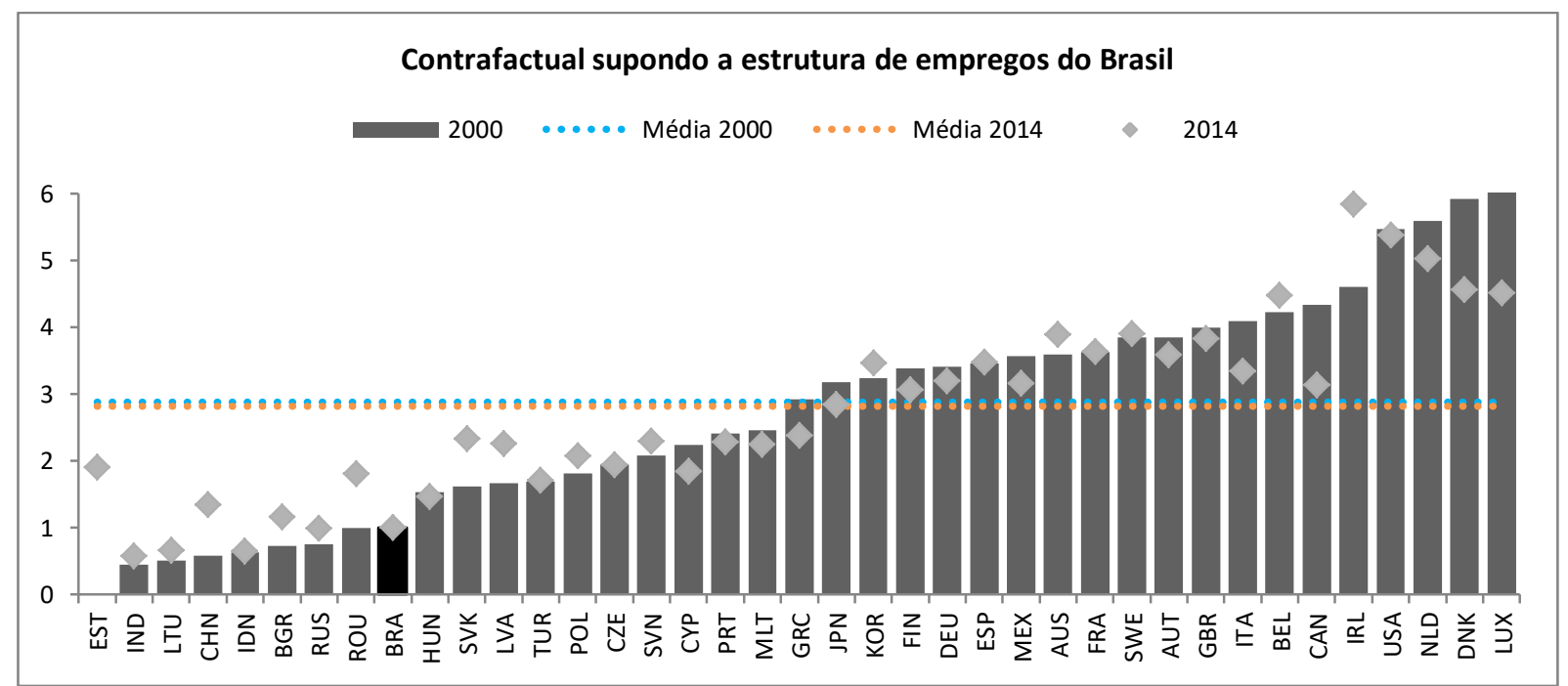

Gráfico 10 - Razões contrafactuais da produtividade do setor moderno do Brasil com países de referência, 2000 e 2014

Notas: Os valores dos eixos diferem entre os dois gráficos. A média exclui o Brasil.

A Tabela 6 resume os resultados até agora reportados da produtividade cruzada para o ano de 2014, indicando os maiores crescimentos da produtividade por diferentes agregações em ambos os exercícios contrafactuais. Nela também é possível verificar as relações entre a produtividade contrafactual do Brasil e a produtividade oficial do país, isto é: (i) casos em que a produtividade contrafactual brasileira passaria a ser maior do que a produtividade oficial do país de referência (caso este país apresente um nível de produtividade maior do que o brasileiro), ou seja, os ganhos de produtividade mais do que compensariam o gap de produtividade original; (ii) casos em que a produtividade contrafactual brasileira passaria a ser maior do que a produtividade brasileira de fato registrada, mas não a ponto de ultrapassar a produtividade do país de referência, ou seja, reduziria o gap de produtividade; e (iii) a produtividade contrafactual do Brasil passaria a ser menor do que o nível oficial da produtividade brasileira (aumentaria o gap de produtividade).

Tabela 6 - Produtividades setoriais contrafactuais e quantidade casos de melhora ou piora por diferentes agregações setoriais em 2014

\begin{tabular}{|c|c|c|c|c|c|c|c|c|}
\hline \multirow{2}{*}{$\begin{array}{l}\text { Agregações } \\
\text { setoriais }\end{array}$} & \multicolumn{4}{|c|}{ Contrafactual 1} & \multicolumn{4}{|c|}{ Contrafactual 2} \\
\hline & $\begin{array}{c}\text { Maior } \\
\text { crescimento }\end{array}$ & $\begin{array}{c}\text { Mais que } \\
\text { compensaria }\end{array}$ & Melhoraria & Pioraria & $\begin{array}{c}\text { Maior } \\
\text { crescimento }\end{array}$ & $\begin{array}{c}\text { Mais que } \\
\text { compensaria }\end{array}$ & Melhoraria & Pioraria \\
\hline Total & TUR (112\%) & 3 & 32 & 4 & USA (444\%) & 7 & 28 & 4 \\
\hline Agropec. & SWE $(14 \%)$ & 0 & 27 & 12 & USA $(1.133 \%)$ & 14 & 16 & 9 \\
\hline Indústria & RUS (82\%) & 1 & 37 & 1 & USA $(534 \%)$ & 4 & 31 & 4 \\
\hline Ind. Transf. & IRL $(48 \%)$ & 0 & 31 & 8 & USA $(664 \%)$ & 5 & 30 & 4 \\
\hline Outras ind. & RUS (127\%) & 6 & 29 & 4 & USA $(404 \%)$ & 8 & 27 & 4 \\
\hline Serviços & IND $(357 \%)$ & 3 & 34 & 2 & LVA (559\%) & 5 & 30 & 4 \\
\hline Serv. Trad. & IND $(526 \%)$ & 3 & 34 & 2 & LVA $(688 \%)$ & 6 & 30 & 3 \\
\hline Serv. Mod. & $\mathrm{CHN}(50 \%)$ & 1 & 8 & 30 & IRL $(727 \%)$ & 16 & 19 & 4 \\
\hline Setor trad. & TUR (194\%) & 2 & 35 & 2 & LVA $(602 \%)$ & 11 & 24 & 4 \\
\hline Setor mod. & RUS $(58 \%)$ & 0 & 31 & 8 & IRL $(485 \%)$ & 5 & 30 & 4 \\
\hline
\end{tabular}

Nota: Os casos incluem a média da SEA, totalizando 39 economias de referência em cada uma das linhas.

Primeiramente, observando a segunda e a sexta colunas da tabela, identificam-se os países de referência que mais trariam ganhos de produtividade para cada um dos exercícios contrafactuais. No primeiro deles, os ganhos potenciais seriam maiores em países com nível de desenvolvimento mais semelhantes do que o Brasil, enquanto que no segundo exercício, os maiores ganhos de produtividade advêm de países de referência com níveis maiores de renda per capita, com predominância dos Estados Unidos, o país mais produtivo. Uma diferença relevante - já discutida anteriormente - consiste nos potenciais ganhos de produtividade em cada um dos contrafactuais. Nas demais colunas é possível verificar a quantidade de casos no ano de 2014 em que as produtividades contrafactuais do Brasil trariam 
ganhos ou prejuízos potenciais para a produtividade do país. Para qualquer dos dois contrafactuais, verifica-se que a ampla maioria dos exercícios traria ganhos potenciais para a produtividade brasileira e, em alguns casos, faria com que a produtividade do Brasil superasse a produtividade do país de referência. Nesse particular, mais uma vez, o segundo contrafactual registra mais casos de compensação do gap de produtividade original do que o primeiro exercício para todas as agregações setoriais.

Por fim, analisam-se os resultados dos mesmos exercícios em relação apenas à produtividade agregada, mas para todos os anos disponíveis (2000-2014) e para todos os países de referência. No que se refere ao primeiro contrafactual, dos 585 casos possíveis (38 países e a média da SEA/WIOD 2016 excluindo o Brasil e 15 anos), em 20 deles (3\% do total) a produtividade do Brasil superaria o nível de produtividade do país de referência (mais do que compensaria a produtividade original do país de referência), em 490 deles $(84 \%)$ a produtividade contrafactual brasileira seria superior à produtividade oficial do Brasil e inferior à produtividade do país de referência e nos 75 casos restantes (13\%) a produtividade contrafactual do Brasil passaria a ser menor do que a observada, de fato. Por seu turno, no segundo exercício contrafactual, em $26 \%$ dos casos (152 no total) o crescimento da produtividade contrafactual mais do que compensaria o nível de produtividade do Brasil e do país de referência, em $63 \%$ (368 casos) a produtividade contrafactual brasileira superaria a oficial do país, mas não a do país de referência, enquanto que em 65 casos $(11 \%)$ a produtividade contrafactual do Brasil seria menor do que a oficial do país. Assim, em $87 \%$ dos casos no primeiro exercício e em $89 \%$ dos casos no segundo exercício o nível contrafactual de produtividade do Brasil seria superior ("melhoraria" ou "mais do que compensaria") ao nível de produtividade brasileira de fato registrado. Isso indica que o baixo nível de produtividade da economia brasileira se deve tanto à sua estrutura de empregos quanto à sua produtividade setorial. Todavia, nos referidos casos de melhora da produtividade agregada do país, os oriundos do segundo exercício são consistentemente superiores em relação ao primeiro exercício contrafactual.

\section{CONSIDERAÇÕES FINAIS}

O presente trabalho teve como objetivo principal investigar alguns motivos estruturais que podem auxiliar na explicação do baixo nível de produtividade do Brasil dos últimos anos, mais precisamente do período 2000-2014. A partir da base de dados da SEA/WIOD 2016 realizaram-se algumas estimações contrafactuais que permitem identificar, para diversas agregações setoriais, se a produtividade da economia brasileira seria maior caso apresentasse uma distribuição da estrutura de empregos semelhante à de outras economias, bem como se apresentasse níveis de produtividades semelhantes aos dessas economias.

É claro que direcionar a estrutura produtiva para setores com maior potencial de crescimento da produtividade agregada não é uma tarefa trivial, tampouco se faz de uma hora para outra, ainda mais sem levar em consideração o contexto histórico e a estrutura institucional, social e política da economia, na medida em que esses fatores influenciam sobremaneira a velocidade e a extensão de qualquer alteração na composição setorial de qualquer país. Também sabe-se da impossibilidade de emular a estrutura econômica de outras economias e implantá-las em um determinado país sem todas as devidas questões apontadas anteriormente. Os resultados contrafactuais apresentados no trabalho servem, em realidade, para elucidar qual alteração dos componentes (estrutura de empregos e produtividade setorial) traria potenciais ganhos de produtividade para a economia brasileira tanto em termos agregados quanto em termos multissetoriais. Em outras palavras, eles servem apenas como indícios e indicações do que o Brasil pode esperar da magnitude desses componentes sobre a sua produtividade. Existe um amplo debate que vem sendo feito há bastante tempo sobre a importância de tais componentes para um crescimento mais virtuoso e sustentado da economia e para auxiliar na explicação do por que a produtividade brasileira é bastante baixa e se estagnou nas últimas décadas, em especial, pelo um suposto esgotamento do processo de mudança estrutural (ou um processo redutor de produtividade) caracterizado pela concentração do emprego em setores menos produtivos na economia brasileira.

A partir dos resultados desse trabalho, verificou-se que o nível de produtividade do Brasil é um dos menores entre as economias da base de dados em praticamente todas as agregações setoriais ou 
mesmo em cada uma das 55 atividades econômicas. Os resultados obtidos trazem algumas evidências de que a alteração em qualquer dos dois componentes trariam ganhos potenciais para a produtividade brasileira em praticamente todos os setores e com praticamente todos os países tomados como referência, desde os mais desenvolvidos quanto, também, de países com níveis similares e menores de renda per capita. Todavia, embora a alteração dos dois componentes traria ganhos potenciais e generalizados de crescimento, o Brasil seria ainda mais produtivo se as suas atividades econômicas tivessem o nível de produtividade setorial dos países de referência. Chama a atenção que esse resultado também é verdadeiro se a economia brasileira passasse a assumir alguns níveis de produtividade setorial de países com níveis mais baixos de renda do que o do Brasil. Nesses termos, apreende-se que a baixa produtividade brasileira é fruto, sobretudo, da baixa produtividade setorial relativamente à alocação do pessoal ocupado entre os setores, resultado esse que está em consonância ao encontrado por Miguez e Moraes (2014) e Veloso et al. (2017). Diferentemente desses dois trabalhos, utilizou-se uma base de dados ainda mais desagregada permitindo investigar com mais profundidade a distribuição da mão de obra e o nível de produtividade setorial em setores bastante heterogêneos por natureza - e mais recente, além de índices setoriais de PPP que permitem comparar de maneira mais adequada níveis de produtividade setorial entre os países. Para além dos ganhos potenciais e generalizados, em ambos os exercícios contrafactuais, em alguns casos, os ganhos de produtividade (agregados e setoriais) seriam mais do que suficientes para eliminar a distância efetiva de produtividade entre os países, deixando o Brasil mais próximo da fronteira de produtividade em todos os segmentos. Esses resultados se tornam ainda mais importantes quando se verifica que nos setores considerados mais nobres, o Brasil está ficando para trás em relação à fronteira tecnológica ao mesmo tempo em que países ainda mais atrasados na corrida da produtividade estão reduzindo a sua distância em relação ao Brasil, até mesmo o ultrapassando, como é o caso da economia chinesa. Isso traz algumas implicações importantes, na medida em que são potenciais competidores e concorrentes do Brasil no mercado internacional em diversos segmentos.

Logo, apesar de o processo de mudança estrutural, isto é, o movimento da mão de obra em direção a setores mais produtivos, ter contribuído historicamente de forma importante para o crescimento da produtividade em todas as economias, sobretudo à época do deslocamento maciço do emprego agrícola para os setores industriais e de serviços, parece que ele, em tempos mais recentes, vem apresentando efeitos limitados sobre a produtividade agregada da economia brasileira, na medida em que a ampliação da produtividade dentro de cada atividade econômica, de acordo com os resultados obtidos nesse trabalho, tenderia a trazer ganhos potenciais muito superiores à economia como um todo. Em assim sendo, entende-se que o problema da baixa produtividade da economia brasileira das últimas décadas decorre fundamentalmente de fatores estruturais e sistêmicos, e não algo associado a setores específicos. Apesar de certas atividades apresentarem maior poder de encadeamento com outras atividades e se mostrarem importantes por diversos motivos, o problema parece estar generalizado entre e dentro dos vários setores.

\section{REFERÊNCIAS}

BAUMOL, W. J. Macroeconomics of unbalanced growth: the anatomy of urban crisis. The American Economic Review, v. 57, n. 3, p. 415-426, 1967.

BONELLI, R. Labor productivity in Brazil during the 1990s. Texto para Discussão IPEA, n. 906, set. 2002.

BONELLI, R. Produtividade e armadilha do lento crescimento. In: DE NEGRI, F.; CAVALCANTE, L. R. (Orgs.) Produtividade no Brasil: desempenhos e determinantes, volume 1. Brasília: ABDI: IPEA, p. 111-141, 2014.

CARVALHEIRO, N. Uma decomposição do aumento da produtividade do trabalho no Brasil durante os anos 90. R. Econ. Contemp., Rio de Janeiro, v. 7, n. 1, p. 81-109, jan.-jun., 2003.

CHENERY, H. B.; ROBINSON, S.; SYRQUIN, M. (Eds.) Industrialization and growth: a comparative study. New York: Oxford University Press, 1986.

CHENERY, H. B.; SYRQUIN, M. Patterns of development. London: Oxford University Press, 1975. 
DE VRIES, G.; TIMMER, M.; de VRIES, K. Structural transformation in Africa: static gains, dynamic losses. The Journal of Development Studies, v. 51, n. 6, p. 674-688, 2015.

CLARK, C., 1940. The conditions of economic progress. London: McMillan \& Co, 1940.

DIETZENBACHER, E.; LOS, B.; STEHRER, R.; TIMMER, M.; DE VRIES, G. J. The Construction of World Input-Output Tables in the WIOD Project, Economic Systems Research, v. 25, n. 01, p. 7198, 2013.

DUARTE, M.; RESTUCCIA, D. The role of the structural transformation in aggregate productivity. The Quarterly Journal of Economics, v. 125, n. 1, p. 129-173, 2010.

FAGERBERG, J. Technological progress, structural change and productivity growth: a comparative study. Structural Change and Economic Dynamics, v. 11, n. 4, p. 393-411, 2000.

FEENSTRA, R. C.; INKLAAR, R.; TIMMER, M. P. The next generation of the Penn World Table. The American Economic Review, v. 105, n. 10, p. 3150-3182, 2015.

FISHER, A. G. Primary, secondary and tertiary production. Economic Record, v. 15, n. 1, p. 24-38, 1939.

HERRENDORF, B.; ROGERSON, R.; VALENTINYI, A. Growth and structural transformation. In: AGHION, P.; DURLAUF, S. N. (Eds.) Handbook of Economic Growth, volume 2B, p. 855-941, 2014.

INKLAAR, R.; TIMMER, M. P. The relative price of services. Review of Income and Wealth, v. 60, n. 4, p. 727-746, 2014.

JACINTO, P. de A.; RIBEIRO, E. P. Crescimento da produtividade no setor de serviços e da indústria no Brasil: dinâmica e heterogeneidade. Economia Aplicada, v. 19, n. 3, p. 401-427, 2015.

KUZNETS, S. Modern economic growth: rate, structure and spread. London: Yale University Press, 1966.

McMILLAN, M.; RODRIK, D. Globalization, structural change and productivity growth. In: BACHETTA, M.; JANSEN, M. (Eds.) Making Globalization Socially Sustainable. Geneva: International Labour Organization, 2011.

MIGUEZ, T.; MORAES, T. Produtividade do trabalho e mudança estrutural: uma comparação internacional com base no World Input-Output Database (WIOD) 1995-2009. In: DE NEGRI, F.; CAVAlCANTE, L. R. (Orgs.) Produtividade no Brasil: desempenho e determinantes, v. 1 Desempenho. Brasília: ABDI: IPEA, 2014.

OCAMPO, J. A.; RADA, C.; TAYLOR, L. Growth and policy in developing countries: a structuralist approach. New York: Columbia University Press, 2009.

PENEDER, M. Industrial structure and aggregate growth. Structural Change and Economic Dynamics, n. 14, p. 427-448, 2003.

PIEPER, U. Deindustrialisation and the social and economic sustainability nexus in developing countries: cross-country evidence on productivity and employment. The Journal of Development Studies, v. 36, n. 4, p. 66-99, 2000.

ROCHA, F. Produtividade do trabalho e mudança estrutural nas indústrias brasileiras extrativa e de transformação, 1970-2001. Revista de Economia Política, v. 27, n. 2, p. 221-241, abr.-jun., 2017.

SQUEFF, G. C.; DE NEGRI, F. Produtividade do trabalho e rigidez estrutural no Brasil nos anos 2000. In: Radar: Tecnologia, Produção e Comércio Exterior. Brasília: IPEA, n. 28, ago. 2013.

TIMMER, M. P.; de VRIES, G. J. Structural change and growth accelerations in Asia and Latin America: a new sectoral data set. Cliometrica, v. 3, n. 2, p. 165-190, 2009.

VELOSO, F.; MATOS, S.; FERREIRA, P. C.; COELHO, B. O Brasil em comparações internacionais de produtividade: uma análise setorial. In: BONELLI, R.; VELOSO, F.; PINHEIRO, A. C. (Orgs.) Anatomia da produtividade no Brasil. Rio de Janeiro: Elsevier: FGV/IBRE, 2017. 